\title{
European structural funds during the crisis: evidence from Southern Italy
}

\author{
Emanuele Ciani ${ }^{1,2^{*}}$ and Guido de Blasio ${ }^{3}$
}

\author{
* Correspondence: \\ emanuele.ciani@bancaditalia.it \\ ${ }^{1}$ Bank of Italy, Regional Economic \\ Research Division, Florence Branch, \\ via dell'Oriuolo 37/39, 50122 \\ Firenze, Italy \\ ${ }^{2}$ Centre for the Analysis of Public \\ Policies, University of Modena and \\ Reggio Emilia, viale Berengario 51, \\ 41121 Modena, Italy \\ Full list of author information is \\ available at the end of the article
}

\begin{abstract}
We investigate the effectiveness of European Structural Funds on employment, population and house prices in 325 Local Labor Markets (LLM) located in Southern Italy. We exploit the variability in disbursements between 2007 and 2013 and estimate the impact of the interventions by allowing for LLM-specific fixed features and LLM-specific time trends. We find that the ability of these funds to offset the negative consequences of the economic crisis seems to have been limited.
\end{abstract}

Keywords: Place-based policies; EU structural funds; Local labor markets

Jel codes: J01; J23; J61

\section{Introduction}

Whether place-based policies should be done is an intriguing topic. Economists seem to be mostly puzzled (see, for instance, Glaeser and Gottlieb 2008; Neumark and Simpson 2014). Nevertheless, supportive arguments have also been proposed (Barca et al. 2012), and policy makers all around the world implement these policies, spending considerable amounts of public money (for instance, \$95 billion annually in the US, according to the figures of Kline and Moretti 2013a).

A prominent example of place-based policies is given by the European Union (EU) Structural Funds (European Regional Development Fund, ERDF, and European Social Fund, ESF), which target disadvantaged areas and use a significant fraction (278 billion, $28 \%$, in the programing period 2007-2013) of the EU budget. Expenditures under the Structural Funds include both investments (transport or telecommunications infrastructures, outlays for innovation, energy, the environment) and labor market programs (aimed at reducing unemployment and increasing human capital and social integration). The bulk of Structural Funds expenditure flows to Objective "Convergence" (former Objective 1) areas, which are EU regions with GDP per capita less than $75 \%$ of the EU average. The aim of the Structural Funds is to increase long-term growth in lagging regions and make it sustainable. Since 2008, however, the EU Commission encouraged using the funds to offset the negative consequences of the economic crisis, through an acceleration of the execution of the programs, originally planned over a 7-year horizon, and a re-orientation of the financing towards counter-cyclical interventions (European Commission 2008a, b).

We investigate the effectiveness of Structural Funds on a number of outcomes (employment, population and house prices), which, according to the theory, should pick up the

(c) 2015 Ciani and de Blasio. Open Access This article is distributed under the terms of the Creative Commons Attribution 4.0 International License (http://creativecommons.org/licenses/by/4.0/), which permits unrestricted use, distribution, and reproduction in any medium, provided you give appropriate credit to the original author(s) and the source, provide a link to the Creative Commons license, and indicate if changes were made. 
bulk of the economic effects of the transfers. A new Italian dataset (www.opencoesione.it) allows us to geo-reference payments relative to projects funded by the European Structural Funds. Unfortunately, comparable data at this detailed level of geo-stratification do not exist for other countries. We focus on 325 Local Labor Markets (LLM) located in Southern Italy, as this is a traditional example of a disadvantaged area in the EU. The choice of considering only Southern regions is motivated by the fact that they were the target of most of the European transfers. In the programing period 2007-13, more than $80 \%$ of the total financing at the national level was allocated to this area. Furthermore, given that one of the main challenges for the evaluation is to address the potentially diverging trends in disadvantaged LLMs, the choice of excluding Northern and Central Italy aims at reducing the degree of heterogeneity. Regions located in the South showed quite different trends in employment, population and house prices during the period of interest, as they were more strongly hit by the recession.

Our identification strategy exploits the variability in disbursements across LLMs between 2007 and 2013. It refers, therefore, to the years of the economic crisis. We estimate the effect of these payments on the growth rates of the outcomes, controlling for both LLM-specific time-invariant features and LLM-specific time trends. In particular, to account for omitted time-varying factors, we include a long set of fixed LLM characteristics interacted with linear and quadratic time trends. Given that this procedure requires including a very long vector of covariates, we select them according to the procedure suggested by Belloni et al. (2014). Including controls for local traits and dynamics should help in isolating the effects of the funds from those associated with the concurrent deteriorating economic conditions experienced by the LLMs during the severe recession.

Our estimates are, basically, diff-in-diffs estimates (with a continuous treatment). In the absence of a policy rule (i.e., a discontinuity) that might allow to isolate the exogenous variation of the transfers, we try to reduce the role of omitted time-varying variables by controlling for an extensive list of LLM-specific traits that should help in predicting local trends. Obviously, our empirical approach might have limitations, insofar one cannot ensure that all the sources of local dynamics are successfully differentiated away. These limitations, however, should be weighed against the benefits of having timely empirical evidence on the effectiveness of the interventions carried out during the current programming period (2007-13) of the EU Structural Funds, which can be also useful to inform the design of the interventions in the next stage (2014-20).

Our results suggest that the EU funding had limited impact on employment. Estimates for the effect of cumulate payments (over 2007-13) on average growth do not detect any effect. Some small increase in employment, however, seems to be associated with the acceleration/re-targeting of payments started in 2011. Across the categories of expenditures, our findings suggest that the EU money channeled through incentives and the purchase of goods and services might have had a slightly more favorable impact on employment compared to money spent on infrastructure. We also do not find any effect whatsoever of the Structural Funds on both population and house prices. The upshot of overall ineffectiveness seems to confirmed even for the LLMs characterized by very low employment or very low initial housing prices. Next, we verify whether a faster disbursement might have implied a more encouraging impact of the scheme on the local economies and find that this is unlikely to be case. We finally show that results do not seem to be affected by the presence of other 
funds, which are available from national sources and are targeted to cohesion purposes as well.

The paper is structured as follows. The next section illustrates the conceptual framework. Section 3 presents the related literature, while the fourth one provides the relevant institutional details. Section 5 describes the identification strategy, while 6 explains the data. The results are illustrated in Section 7. Concluding thoughts are offered in Section 8.

\section{Conceptual framework}

Place-based policies aim to spur development in underperforming areas. Theoretically, market imperfections can potentially justify public intervention. A classic example refers to the under-provision of public goods (e.g., roads) by the private sector. Another instance is that of labor markets with search frictions and hiring costs, where place-based hiring subsidies may improve efficiency if introduced in those areas where the productivity of a match is lower (Kline and Moretti 2013b). A list of other potential justifications for interventions, ranging from agglomeration economies to network effects, can be found, for instance, in Kline and Moretti (2013a) and Neumark and Simpson (2014). The bottom line is that "localized" market failures, of any nature, can be addressed by "localized," or place-based, policies. This amounts to say that, on theoretical grounds, place-based policies might have the potential to increase local efficiency.

Obviously, market imperfections can be difficult to detect. Economically disadvantaged areas usually feature several market failures, rather than a single one, so it is not clear what the priority of the policies should be. Moreover, interventions that aim to modify the incentives for the private agents, such as a subsidy scheme, may not be effective or may induce unintended behavior (see, for instance, the literature review in Accetturo and de Blasio 2012). Most of the time, the households and firms' behavior is similar to the one they would show in the counterfactual scenario of no scheme. Finally, political economy mechanisms (see Krueger 1974, Signorini and Visco 2002, and Besley 2004) suggest that transferring resources to disadvantaged areas could itself be harmful because it might enhance rent-seeking and increase the payoff for deviant behaviors (such as corruption).

Whether place-based policies increase local efficiency is, therefore, an empirical question. Employment is a natural proxy to measure the impact of the interventions because many such programs list job creation for local residents as one of the primary objectives. However, there could be benefits to the local community that are not capitalized in additional employment. Roback-type models of spatial equilibrium (Glaeser 2008) highlight that the presence of location-specific factors positively related to firms' productivity and households' welfare will result in higher prices for non-tradable factors, such as housing. The dynamic of population is also an interesting outcome to look at, given that residential choices are motivated by the benefits accruing to mobile households. For these reasons, our empirical investigation provides a joint assessment of the impact of the Structural Funds on employment, population movements and house prices. Looking at the three outcomes at the same time should also help in disentangling the equity implications of the interventions. Standard spatial equilibrium models predict that, in a world where workers are perfectly mobile and housing supply is completely inelastic, the entire benefits of placebased policies will be picked up by housing values. Less extreme circumstances - such as less mobile workers or elastic housing - imply that the intervention can affect the utility of infra-marginal workers. 


\section{Links with the related literature}

Neumark and Simpson (2014) provide an up-to-date review of the evaluation studies carried out for place-based policies. More related to our paper, a number of studies refer to evaluations at the EU-wide level. By using standard regression techniques, the effectiveness of the EU financing for regional GDP growth was questioned by Boldrin and Canova (2001) and Sala-i-Martin (1996). Recently, however, by employing RDD (regression discontinuity design) identification strategies that exploit the 75\% threshold for Objective 1 (which is the bulk of cohesion policy and European transfers) eligibility, Becker et al. (2010) and Pellegrini et al. (2013) argue that the receipt of Structural Funds is associated with an annual per capita GDP increase of about 1-1.5 percentage points over a EU programing period (7 years). On the other hand, Accetturo et al. (2014), using the same empirical framework, show that transfers might have unintended consequences on the local endowments of social capital and cooperation. While the credibility at the threshold of these exercises is typically not an issue, the external validity for regions far from the cutoff is a major drawback, especially for exercises that aim to inform policy. A step forward towards results that can be deemed as more general is the study by Becker et al. (2012), which uses GPS (generalized propensity score) methods and finds that effectiveness is a scattered upshot in the European landscape and that for a number of regions a reduction of the EU funding would not reduce their growth. Finally, Becker et al. (2013) show that the effect estimated exploiting the RDD design is highly heterogeneous at the threshold, as it depends strongly on the absorptive capacity of a region, as measured by human capital and the quality of institutions. Areas characterized by low absorptive capacity display a small and not significant effect, while the gains are concentrated in a subset of lagging-behind regions who have relatively better institutions and/or human capital.

Another stream of empirical investigations refers to specific place-based policies implemented in Italy, and financed (at least partially) with EU money. In this case, the evidence seems to be less encouraging. Bronzini and de Blasio (2006) find that a major incentive scheme (Law 488/1992) intended to subsidize firms located in economically depressed areas had only little impact on firms' investment. Accetturo and de Blasio (2012) suggest that "Patti Territoriali," a program based on a bottom-up approach with the local community playing a leading role in designing the development plan, made no difference for the economic fortunes of the areas. Andini and de Blasio (2014) argue that "Contratti di Programma," an intervention by means of which the Government approves and finances industrial projects proposed by private firms, had limited effects on local growth (and mostly at the expenses of the surrounding territories). Finally, the only paper that deals with overall EU funding effectiveness in Italy, irrespective of the specific program through which the money is channeled into the economy, is Giua (2014). She considers in a RDD set-up the differences in employment growth across municipalities on the two sides of the Objective 1 border and finds a positive impact on employment.

Compared with the previous literature, our paper has a number of novelties. Firstly, it uses data from the 2007-13 EU programing period. All the previous empirical studies refer to older programing periods. Thanks to the availability of high-quality data (with localization details) of the website OpenCoesione, we are able to estimate the impact of the EU funding on a number of local outcomes, which, at the time of writing, are measurable until 2013. Our estimation window covers the period of the financial and economic crisis. Therefore, our findings provide hints about the countercyclical impact of the EU 
policy rather than suggestions for the medium-term consequences of the interventions. Indeed, as we explain below, many programs were re-targeted explicitly to address the strains of the downturn. Given that we are studying a timespan of exceptional economic circumstances, it might be hard to imagine that our findings could provide lessons for periods with less extreme conditions.

Secondly, and differently from the papers based on a RDD-type framework, our inference refers to the universe of Southern Italy's areas covered under the policy, not only to those close to thresholds of eligibility.

Thirdly, we provide an evaluation of the impact of the EU structural funds taken as a whole, irrespective of the specific programs through which the money is channeled, although we also document the differential impacts for some broad categories of expenditure. In this respect, our paper shares the motivation of the studies that up to now have been conducted at the EU-wide level. With respect to them, the main limitation is that we focus on a single area: the South of Italy. On the one hand, our restricted focus limits the possibility of drawing lessons for other EU countries. On the other hand, it limits the amount of unobserved heterogeneity that may bias the results.

\section{Institutional details}

The Structural Funds represent financial instruments of the EU regional policy, intended to pursue the goal of economic, social and territorial cohesion by narrowing the development disparities among regions and member states. For the period 2007-2013, the budget allocated to the Structural Funds amounts to around $€ 278$ billion, which represents $28 \%$ of the Community budget. There are two Structural Funds: the European Regional Development Fund (ERDF), set up in 1975, providing support for the creation of infrastructures and productive job-creating investment, mainly for businesses; the European Social Fund (ESF), set up in 1958, contributes to the integration into working life of the unemployed and disadvantaged sections of the population, mainly by funding training measures. The bulk of Structural Funds expenditure flows to Objective "Convergence" (former Objective 1) areas, which are EU regions with GDP per capita less than $75 \%$ of the EU average. Structural Funds always involve co-financing from national sources.

The aim of the EU Structural Funds is to increase long-term sustainable growth of the lagging areas. However, soon after the outbreak of the crisis, the European Commission put forward a recovery plan in which it encouraged the use of EU Structural Funds for counter-cyclical aims (European Commission 2008a, b). In particular, the Commission suggested increasing the spending through the combination of both EU funding and national budgetary stimulus packages, which should be coordinated in order to avoid negative spillovers across countries (European Commission 2008a). With regard to money available for the cohesion policy, the recovery plan envisaged to accelerate program implementation rather than to increase funding per se. It translated into an ease of administrative procedures, an increase of projects pre-financing and a decrease of national co-funding share, allowing countries to increase up-front spending as the pressure on national budget constraints is reduced. The Commission encouraged member States to "re-prioritize" cohesion investments in view of the ongoing turbulent economic situation: it invited national governments "to explore possible changes in priorities and objectives with a view to accelerate the spending in the areas with more growth potential. This could include more focus on energy efficiency measures, including in housing, and strengthening the focus of support 
for small and medium enterprises, which are the main motor for growth in the European economy." (European Commission 2008b, pg. 4).

With the 2011 "Piano di Azione e Coesione," (see resolution 1/2011 of the Inter-ministry Committee for the Economic Planning, "CIPE"), the Italian Government followed the EU suggestion. A number of actions were taken, both to ensure faster spending (also through ring-fencing of specific programs, which execution was moved from local to national competencies) and re-focusing the existent programs towards counter-cyclical aims, among which wage supplementation schemes and subsidies to SMEs had a prominent role.

\section{Identification strategy}

We focus on the effect of payments related to the European Structural Funds on the growth $\Delta y_{i t}$ in employment, population and housing prices at the local level. Here the subscript $i$ refers to the Local Labor Markets (LLMs), which are geographical areas designed by the National Statistical Institute to be approximately a self-contained commuting zone (Istat 1997). Each LLM is defined by aggregating municipalities through an algorithm that, on the basis of commuting to work matrices built from the 2001 Population Census, maximizes the share of resident commuters that move only between municipalities within the LLM (the supply side) and the share of workers that come from within the LLM (the demand side). ${ }^{1}$ The algorithm does not impose contiguity, which is obtained ex-post by reallocating ad-hoc the small number of municipalities (less than 1\%) that are assigned by the algorithm to a non-contiguous LLM. We defer to Istat (1997) for a more detailed description.

We restrict our analysis to the 325 LLMs that are located in Southern Italy, which includes eight regions: Abruzzo, Molise, Campania, Puglia, Basilicata, Calabria, Sicily and Sardinia. LLMs are not constrained to administrative boundaries, and, therefore, one LLM may contain municipalities that belong to different regions. For the definition of Southern Italy, we included only LLMs for which the central municipality (defined as the one which attracts the most commuters from other municipalities) belongs to the listed regions. In practice, the overlapping is rather limited. We excluded 13 small municipalities (with a population amounting to around the $0.3 \%$ of residents in Southern regions in 2007) that belong to Southern regions but are part of LLMs that do not match our definition of "Southern Italy LLMs." On the opposite, we included $7(0.04 \%$ of residents in Southern regions in 2007) that are part of Central Italy, but are included in the LLM named after Avezzano, a town located in Abruzzo.

The first difference operator $\Delta$ refers to a proportional change (growth). We estimate the effect of annual per-capita payments $\boldsymbol{d}_{\boldsymbol{i t}}$ on annual growth, taking 2007 as the starting point (see Section 6 for a discussion of this choice):

$$
\begin{aligned}
& \Delta y_{i t}=\delta \ln \left(d_{i t}\right)+\gamma_{t}+\Delta \varepsilon_{i t} \\
& \Delta y_{i t}=\frac{y_{i t}-y_{i t-1}}{y_{i t-1}} \\
& E\left(\Delta \varepsilon_{i t} \mid \ln \left(d_{i t}\right), \gamma_{t}\right)=0,
\end{aligned}
$$

where $t=2008, \ldots, 2013$. To account for the overall effect, we also estimate the impact of cumulative per-capita payments $c_{i}$ on the average 2008-13 growth in outcomes 


$$
\begin{aligned}
& \Delta^{6} y_{i}=\delta \ln \left(c_{i}\right)+\gamma_{0}+\Delta \varepsilon_{i} \\
& \Delta^{6} y_{i}=\left(\frac{y_{i 2013}}{y_{i 2007}}\right)^{1 / 6}-1 \\
& E\left(\Delta \varepsilon_{i} \mid \ln \left(c_{i}\right), \gamma_{0}\right)=0
\end{aligned}
$$

The focus on the average growth rates allows us to account for the possibility that the impact of EU funding spreads over the entire period (in section 7.8 we also estimate yearto-year models including lags of $\ln \left(d_{i t}\right)$ ). From the econometric point of view, the use of both average and annual growth is important because it allows us to exploit alternatively both sources of variability, cross-sectional (between LLMs) and overtime (within LLMs).

The main problem with both regressions (1) and (4) is that more funds may have been transferred to those LLMs that would have shown, even in the absence of the policy, a stronger negative trend. This might well be the case since (part of) the original allocation of funds has been re-targeted and the disbursement accelerated to fulfill countercyclical purposes (see Section 4). ${ }^{2}$ Available solutions to this problem depend on the type of specification (year-to-year or average) adopted.

\subsection{Solutions for local time-varying omitted variables for the year-to-year specifications}

By exploiting the year-to-year variability as in equation (1), we can experiment with a number of different strategies. First of all, we can control for LLM-specific linear time trends by adding fixed effects $g_{i}$, which would capture a constant growth over the years for each LLM:

$$
\Delta y_{i t}=\delta \ln \left(d_{i t}\right)+\gamma_{t}+g_{i}+\Delta \varepsilon_{i t} .
$$

For equation (7) to be consistently estimated by OLS, we need a strict exogeneity condition:

$$
E\left[\Delta \varepsilon_{i s} \mid \ln \left(d_{i t}\right), \gamma_{t}, g_{i}\right]=0 \quad \forall s, t .
$$

Shocks $\Delta \varepsilon_{i t}$ must be, conditional on time and LLM effects $\gamma_{t}$ and $g_{i}$, uncorrelated with payments in all time periods. This condition means that current payments should be unrelated not only with current shocks on the local economy, but also with past and future shocks. The latter scenario is not unreasonable: it is likely that areas where the recession was stronger felt have been able to attract more payments later. To check whether strict exogeneity holds with our data, we run the test suggested by Wooldridge (2010, p. 325), which amounts to adding the lead of the covariate of interest and test whether it is significant in the regression.

The introduction of fixed effects in eq. (7) captures LLM-specific linear trends. However, there may be quadratic or cubic trends that would require introducing additional interactions between the LLM fixed effects and higher order time trends in the regression. This is not feasible given the short length of our data. We exploit a different strategy, based on a set of time-invariant covariates $f_{i}^{\prime}$. We introduce them in a year-toyear regression, and we also interact them with a linear time trend $t$ and its square. Given that the regression is already in first difference, this allows for linear, quadratic and cubic trends that depend on these pre-determined variables: 


$$
\Delta y_{i t}=\delta \ln \left(d_{i t}\right)+\gamma_{t}+f_{i}^{\prime} \omega_{1}+t \times f_{i}^{\prime} \omega_{2}+t^{2} \times f_{i}^{\prime} \omega_{3}+\Delta \varepsilon_{i t} .
$$

In this case, the necessary exogeneity condition is:

$$
E\left(\Delta \varepsilon_{i t} \mid \ln \left(d_{i t}\right), \gamma_{t}, f_{i}^{\prime}, t\right)=0 .
$$

Condition (10) differs from the one required for FE estimation. On the one hand, it allows for higher order time trends (although in a simplified way), and it does not require strict exogeneity (only the error $\Delta \varepsilon_{i t}$ at time $t$ has to be uncorrelated with payments at time $t$ ). On the other hand, it requires covariates included in $f_{i}{ }^{\prime}$ to be good proxies of the unobservable so that the OLS coefficient on $\ln \left(d_{i t}\right)$ is a consistent estimator for the true effect of the payments.

The vector $f_{i}^{\prime}$ includes an extensive set of local variables, which are time-invariant: employment, unemployment and activity rates in 2004, 2005, 2006 and 2007; (log of) the outcomes (employment, population and house prices) in 2004, 2005, 2006 and 2007; the growth of the outcomes over 2004-07; the total surface (in kmq), population density in 2007, average altitude, the fraction of the surface composed of mountain municipalities and that referring to municipalities located on the coast, total number of houses per capita (census 2001 on population 2007) and total number of empty houses per capita (census 2001 on population 2007). In order to account for differential cyclical trends, we also control for sector composition by including the 2007 share of private workers in construction, trade services, and other services (considering manufacturing as the excluded category). ${ }^{3}$ Finally, we also add the logarithm (and its square) of the public funds that were allocated at the beginning of the programing period. This variable captures additional pre-treatment heterogeneity, as higher allocations reflect deeper underperformances. Furthermore, conditioning on it, we are able to capture the effect of actual spending given the theoretically available funds. This is an interesting quantity, given that most of the recent policy debate was focused on the ability of using the most of the available funds (see, also, section 7.5).

The strategy of including LLM characteristics interacted with time trends, as argued by Belloni et al. (2014), implies adding a very long set of covariates, which may hinder the precision of the estimators and create problems for standard inference. The authors suggest the selection of a smaller set of variables using a "double selection method." Instead of assuming that one needs to control for the entire list of variables $\left(f_{i}^{\prime}, t \times f_{i}^{\prime}, t^{2} \times f_{i}^{\prime}\right)$, they assume that there is a smaller set of covariates such that, once controlling for them, $\ln \left(d_{i t}\right)$ can be considered exogenous. The problem is that this subset is a priori unknown. The standard procedure would be to consider only those variables that the researcher or the literature consider more relevant. Differently, Belloni et al. (2014) propose to select them by using a Least Absolute Shrinkage and Selection Operator (LASSO), which minimizes the sum of squared residuals and an additional penalty parameter that aims to reduce the overall size of the model. We defer to their paper for details about the operator. ${ }^{4}$ The selection must be conducted on the two reduced forms

$$
\begin{aligned}
& \Delta y_{i t}=\beta_{t}^{y}+f_{i}^{\prime} \beta_{1}^{y}+t \times f_{i}^{\prime} \beta_{2}^{y}+t^{2} \times f_{i}^{\prime} \beta_{3}^{y}+\Delta v_{i t}^{y} \\
& \ln \left(d_{i t}\right)=\beta_{t}^{d}+f_{i}^{\prime} \beta_{1}^{d}+t \times f_{i}^{\prime} \beta_{2}^{d}+t^{2} \times f_{i}^{\prime} \beta_{3}^{d}+\Delta v_{i t}^{d},
\end{aligned}
$$

and the final set of variables should be the union of those selected in (11) and (12). The reason is that the selection aims to maximize the predictive power of the 
covariates, which is captured by the reduced forms rather than by the equation of interest (9).

\subsection{Solutions for local time-varying omitted variables for the average growth specifications}

In eq. (4) it is not possible to introduce LLM fixed-effects. We can therefore only add the vector of LLM-specific time-invariant variables $f_{i}^{\prime}$. Given that the regression is in first-differences, introducing these covariates allows for counterfactual linear time trends that depends on pre-determined differences in these variables:

$$
\Delta^{6} y_{i}=\delta \ln \left(c_{i}\right)+\gamma_{0}+f_{i}^{\prime} \omega+\Delta \varepsilon_{i} .
$$

For OLS to consistently estimate the true effect of cumulative payments, we need payments and shocks $\Delta \varepsilon_{i t}$ to be uncorrelated given the LLM characteristics included in $f_{i}^{\prime}$. Additionally, we also implement the Belloni et al. (2014) procedure to estimate eq. (13).

\section{Data and descriptive statistics}

The information on payments and allocations comes from the OpenCoesione website. ${ }^{5}$ It collects all the information relative to projects at least partially funded by EU Structural Funds. The variable on payments not only include the money coming from the European funds, but also the co-financing from the Italian Government (or local authorities) and, in some cases, from the private sector. Importantly, the data provides geo-referenced information about the targeted places. Although the majority of the projects (around 97\%) take place at the level of municipalities, in some cases they refer to the higher administrative levels of provinces or regions. ${ }^{6}$ In these cases, we reallocated the spending to the municipalities on the basis of the 2007 population. Projects at the national level have been excluded. Given that we use geographical variation as source of heterogeneity, they would be of no help in estimating the effect. Anyway, at the end of 2013 the cumulative payments relative to projects at the national level amounted to only $2.3 \%$ of those relative to projects at the sub-national level, which we use in the analysis.

In the cases in which national funds were used for projects funded also through EU Structural Funds, the relative money (co-financing) is already included in our variable. There are nevertheless some projects that are only funded by national sources (in particular, the "Fondo per lo Sviluppo e la Coesione"). Their role seems to be limited. For Southern Italy the cumulative payments over 2007-13 relative to national funds only amounted to 0.6 billion euros against a total of 19.4 billion euros relative to projects funded at least partially by EU Funds. We decided not to include expenditures only financed by national sources in our main regressions because they follow procedures different from the ones where EU money is at stake, but we conducted a robustness check by adding them (see: para. 7.6). All variables relative to payments are expressed in per-capita terms, using only the population in 2007 as the denominator.

In the regressions for annual growth, we focus only on changes and transfers over the period 2008-13, taking year 2007 at the starting point. Although some payment were also made during that year, their impact is likely to be negligible: with regard to Southern LLMs, only 400 million was spent in 2007 , which is $1.7 \%$ of the total expenditure over the entire period. 
Employment figures come from the Istat Labor Force Survey, while the local population is obtained from Istat Intercensus demographic balance reconstruction. House prices per sqm come from the Osservatorio Immobiliare. Data were aggregated at the municipality level with the procedure described in Cannari and Faiella (2008). Given that they are released every semester, we took a simple average over the whole year. In order to aggregate them at the LLM level, we use the 2007 local population as a weight.

We did not make substantial alterations to the original data. We only censored the annual changes in house prices at the $1^{\text {st }}$ and $99^{\text {th }}$ percentile of the overall pooled distribution because there were some relevant outliers. In some LLMs in a few years the annual payments were zero or less than one euro per-capita, and they could also be negative in the case of reimbursement of previous payments relative to projects that were stopped. These are overall very few cases: the LLM-year observations with payments amounting to less than one euro per-capita were less than one percent in the total pooled sample and around $3 \%$ in 2008 , and there was only one case with a small per-capita negative payment. We simply imposed the logarithm to be zero in those years. Log cumulate payments are positive in all LLMs.

Figure 1 shows the trends in the outcomes over the entire period in the Southern Italy. Employment decreases significantly by approximately 10\%. Population remains approximately constant, with a small smooth increase. House prices initially increase in 2008; they do not decrease much during the initial part of the crisis, while they decline by around 5\% during the last two years. Payments relative to projects financed by EU Structural Funds appear to be countercyclical. They are negligible in 2007, they start to be economically significant in 2008 and then they increase in 2009-10. In 2011 we observe a significant increase, up to 200 euros per capita, which follows the actions taken by the Italian government to speed-up the spending and refocusing the programs (see Section 4). The increase in payments is made clear in Fig. 2, which shows the distribution of payments across LLMs by year. The amount of transfers remained at the higher level during 2012 and 2013. The variability over time and across areas is quite substantial. Given that

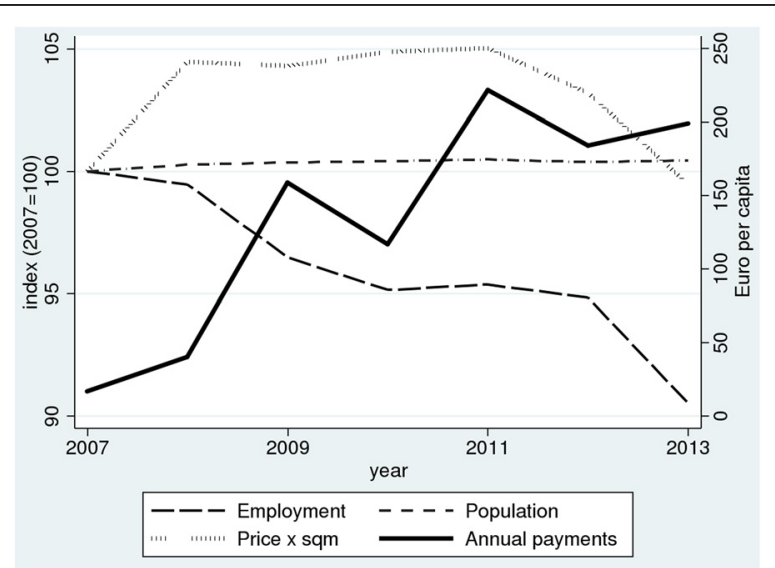

Fig. 1 Annual European Structural Funds payments (euro/capita, right axis) and trends in employment, population and house prices (index $2007=100$, left axis), 2007-2013, Southern Italy; Notes: Annual payments are per-capita, calculated divided total payments to Southern Italy by total Southern population in 2007. Employment data are from Labor Force Surveys, house price per sqm from Osservatorio Immobiliare (aggregated at the area level by weighting with 2007 population), population from Istat intercensus reconstruction, annual payments from Opencoesione website 

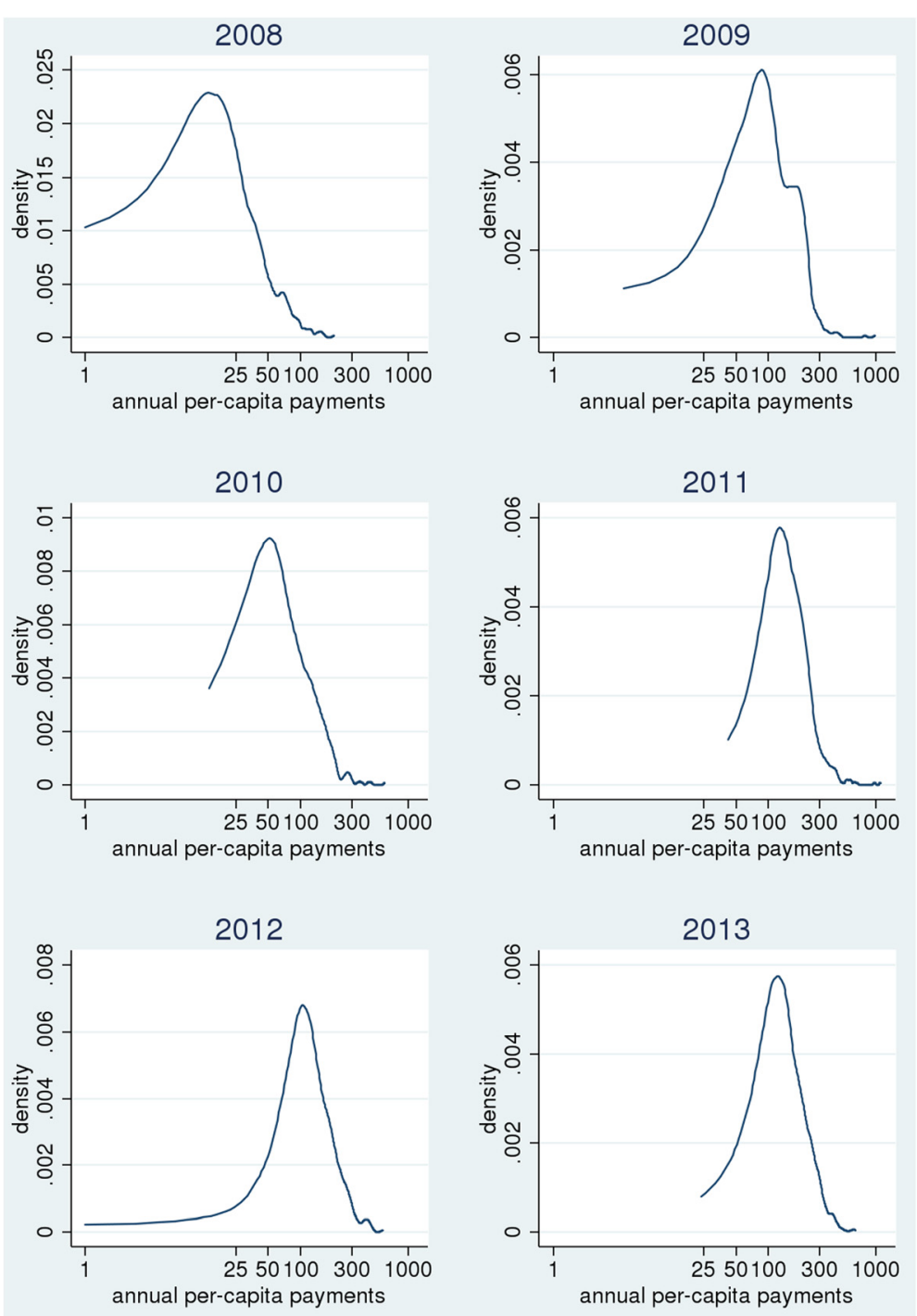

Fig. 2 Density of annual per-capita payments, Southern Italy LLMs; Notes: Payments are on a log-scale. Densities are estimated using a kernel density estimator and Silverman's rule of thumb bandwidth

in some estimates we introduce LLM fixed effects, it is also important to discuss the size of variability within single local areas. In the overall sample, the within LLMs variance accounts for $44 \%$ of the total variance (after removing year fixed effects). The fraction is still very similar (40\%) if we exclude the first year, when payments were lower. It remains quite high even if we consider single pair of years (around 15-20\%).

Figure 3 displays the geographical pattern of the cumulative per-capita payments over 2007-13. The heterogeneity is quite substantial, also between LLMs located next to each other. Puglia (South-East) and Calabria (the last part of mainland before Sicily), both part of the "Convergence" target, are characterized by a stronger intensity of per-capita payments in most of their LLMs. The other two "Convergence" regions, Campania (in the mainland on the West coast) and Sicily received substantial amount of funding, but they are more concentrated in specific LLMs (e.g., the area of Naples in Campania). Sardinia, despite not being part of the core "Converge" regions, managed to spend a large fraction 


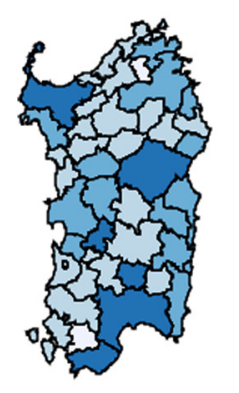

0

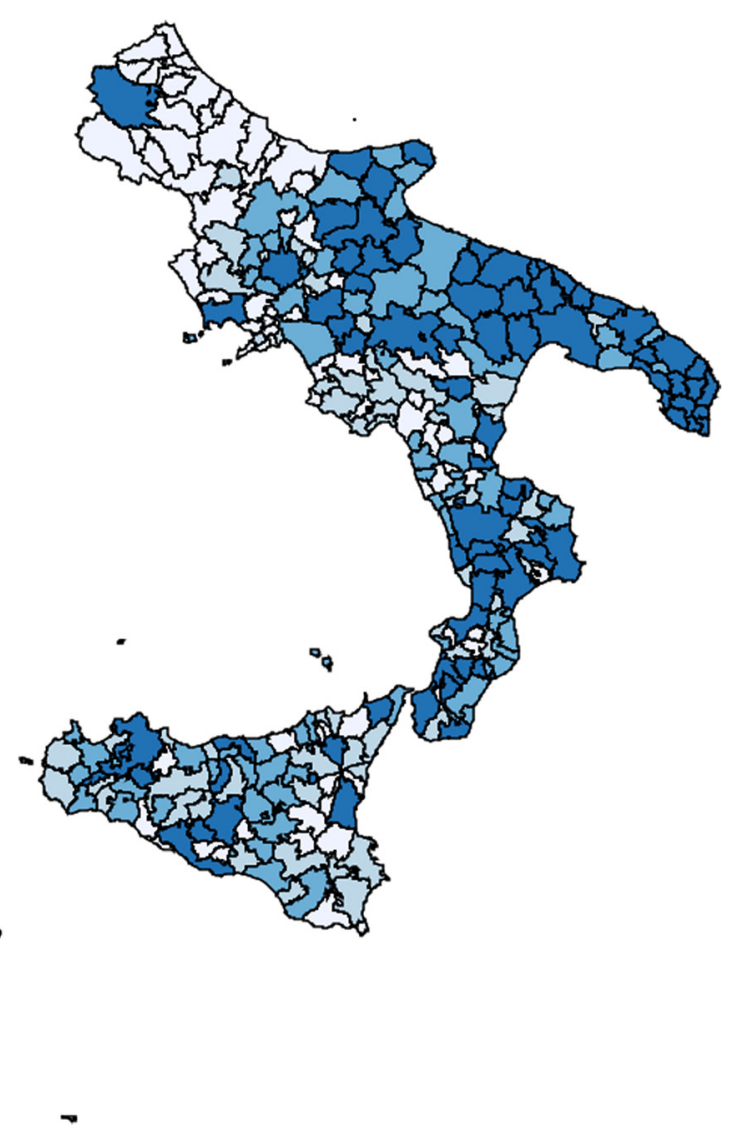

Fig. 3 Map of the Southern Italy LLMs by quartile of the cumulative per-capita payments over 2007-13 (intervals in euro)

of it. The other areas are less covered by transfers, in particular the region of Abruzzo, located at the top of the map (in the mainland), although some local labor markets still received significant amounts of payments.

Figure 4 displays the scatterplot and raw correlation between growth in output and the logarithm of per-capita payments. Growth rates have been detrended by removing averages across all LLMs to account for the overall trend that would induce a strong negative correlation between annual changes in employment and cumulate payments. Annual growth in outcomes does not display any significant relation with payments: basically, linear fits are flat and the scatterplot does not highlight any particular relation (nor sensible outliers). Average growth seems to be negatively correlated with cumulative percapita payments over 2007-13, while the relationships with population and house prices are not statistically significant (though respectively positive and negative).

Additional descriptive statistics on variables of interest are reported in the Additional file 1.

\section{Results}

\subsection{Main results}

Table 1 shows simple regressions of the growth in the outcomes over the logarithm of the flow of per-capita payments. The annual growth rates (Columns 1, 2, and 3) display no 

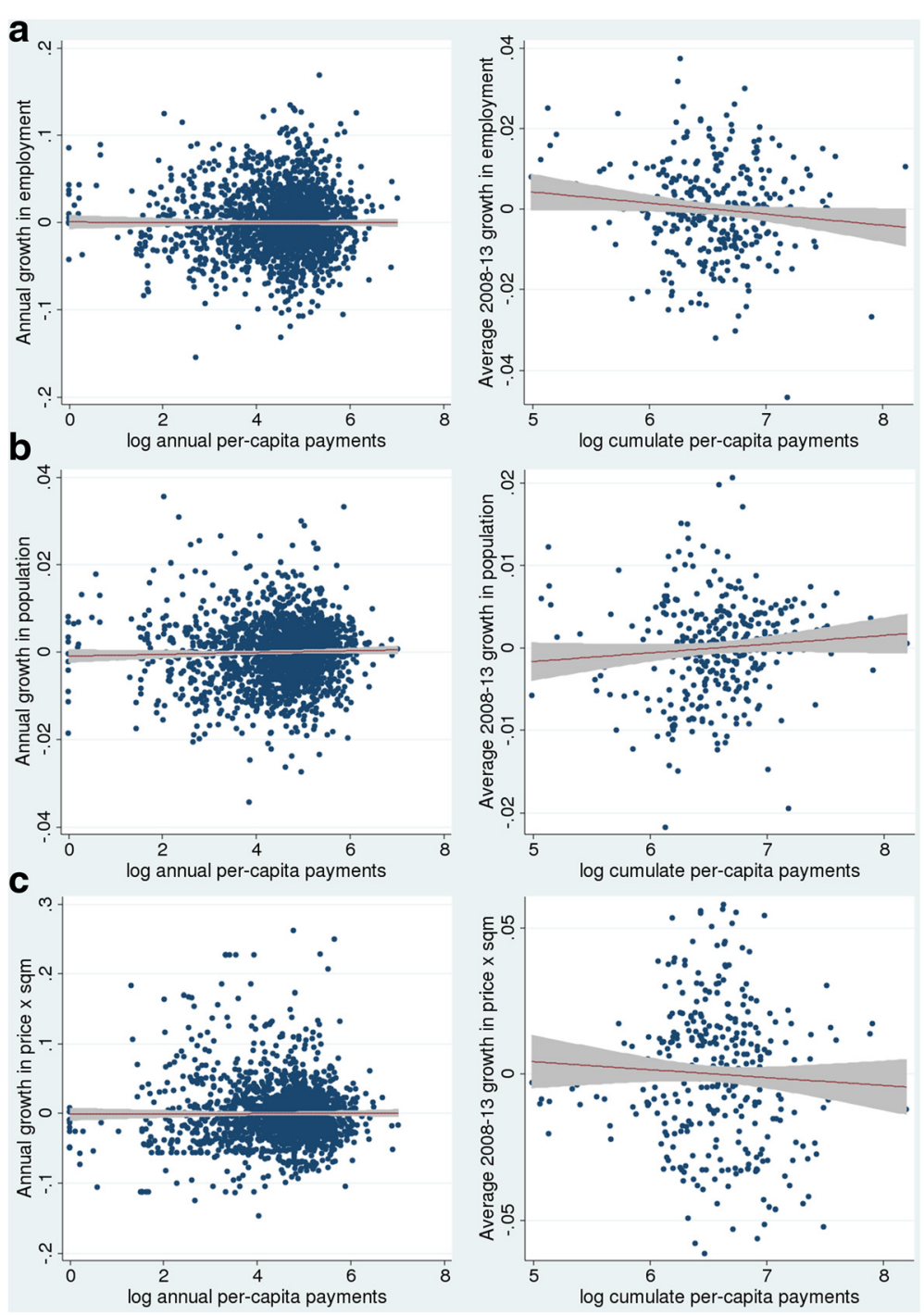

Fig. 4 Growth in employment, population, and house prices in Southern Italy LLMs with respect to per-capita European Structural funds payments. Annual growth on the left and average 2008-2013 growth on the right; a Employment $\mathbf{b}$ Population c House price per sqm; Notes: Growth rates are detrended by removing the average (by year for annual changes) across all LLMs. See Table 1 for data sources. Average 2008-13 is a geometric average. Figures display a linear fit with 95\% confidence interval (s.e. clustered at the LLM level)

significant correlation, with negligible coefficients from the economic perspective. Differently, in Column 4, where we consider the average outcome growth, a $10 \%$ increase in per-capita cumulative payments (equivalent to approximately 76 euros if evaluated at the average among LLMs) is associated with a $0.027 \%$ decrease in employment. This correlation is in line with the possibility that funds have been directed towards those areas that have been hit more strongly by the crisis. Population and house prices (specifications 5 and 6) do not show any association with cumulative funds over the entire period.

Table 2 shows the regression results relative to annual growth in the outcomes (the variable of interest is the log of annual per-capita flow of payments). For each outcome, we start by introducing FE to account for linear trends. Then we add both $f_{i}^{\prime}$ and a full set of interactions with $t$ and $t^{2}$ to account for higher order time trends. Finally, we 
Table 1 The effects of European Structural Funds, Southern Italy, 2008-2013

\begin{tabular}{|c|c|c|c|c|c|c|}
\hline & (1) & (2) & (3) & (4) & (5) & (6) \\
\hline & \multicolumn{3}{|c|}{ Annual 2008-2013 growth in: } & \multicolumn{3}{|c|}{ Average 2008-2013 growth in: } \\
\hline & Employment & Population & $\begin{array}{l}\text { House price } \\
\text { per sqm }\end{array}$ & Employment & Population & $\begin{array}{l}\text { House price } \\
\text { per sqm }\end{array}$ \\
\hline \multirow{2}{*}{$\begin{array}{l}\text { In(annual per capita } \\
\text { payments) }\end{array}$} & -0.0002 & 0.0004 & 0.0004 & & & \\
\hline & $(0.0010)$ & $(0.0003)$ & $(0.0015)$ & & & \\
\hline \multirow{2}{*}{$\begin{array}{l}\text { In(cumulative per capita } \\
\text { payments } 07-13 \text { ) }\end{array}$} & & & & $-0.0027^{* *}$ & 0.0011 & -0.0027 \\
\hline & & & & $(0.0013)$ & $(0.0007)$ & $(0.0023)$ \\
\hline Obs & 1950 & 1950 & 1950 & 325 & 325 & 325 \\
\hline R2 & 0.2152 & 0.0471 & 0.2460 & 0.0124 & 0.0069 & 0.0029 \\
\hline
\end{tabular}

Note:

The unit of observation is the LLM over time. Data on payments come from Open-coesione. Employment refers to the average annual employment from the LFS survey. Population is obtained from ISTAT data (inter-census reconstruction). Price per square meter is from OMl, aggregated at the municipality level using the method described in Cannari and Faiella (2008). The regressions include a constant and year fixed effects. Standard errors clustered for LLM in parentheses (robust s.e. for average growth). The average growth over $2008-13$ is calculated as a geometric average ${ }^{*} p<.10{ }^{* *} p<.05{ }^{* * *} p<.01$

select only a subset of these variables by using the "double selection" method of Belloni et al. (2014). There seems to be no evidence of an effect of the EU funding on employment (Columns 1, 2, and 3). FE estimates seem to uncover an effect on population (Column 4) and house prices (Column 7), but they disappear when we introduce covariates interacted with time trends (Columns 5 and 8, respectively). The absence of any effect is confirmed by focusing only on the subset of selected covariates, which are reported (Columns 6 and 9). It is important to highlight that the "double selection" keeps some interactions with the time trend only for the house price regression, suggesting that heterogeneous time trends are particularly important for this outcome. With regard to FE estimates, the strict exogeneity test does not suggest any particular problem, as we fail to reject the null that the lead of annual per capita payments is not significant when added to the regression.

Table 3 displays the results from regressions for the average growth on the log of cumulative per-capita payments. For each outcome we show specifications that alternatively include the full set of pre-determined variables $f_{i}^{\prime}$ to account for potentially different trends during the recession and only the subset of covariates selected using Belloni et al.'s (2014) "double selection" strategy. As for employment (Columns 1 and 2), we find a coefficient on $(\log )$ cumulative per-capita payments that is very small and not statistically significant. The negative effect found without controlling for time-varying proxies (Table 1, Column 4) disappears. However, the absence of an effect on population (Columns 3 and 4) is confirmed. Differently from Table 1, Column 6, the inclusion of covariates (Column 5 and 6) seems to uncover a negative effect on house prices.

We also experimented by restricting the analysis to those regions belonging to the "Convergence" objective (Calabria, Campania, Puglia and Sicily), which are the most disadvantaged areas where the bulk of the available funding is allocated. ${ }^{7}$ Results (available upon request) for average growth and cumulate per-capita payments are similar to those presented in Table 3, apart from a negative, but statistically significant only at the $10 \%$ level, coefficient in the employment regression. Regressions for annual growth confirm the main findings from Table 2 , with all the coefficients neither statistically nor economically significant. 
Table 2 The effects of European Structural Funds on annual growth, controlling for LLM time invariant characteristics and differential time trends

\begin{tabular}{|c|c|c|c|c|c|c|c|c|c|}
\hline \multirow{2}{*}{$\begin{array}{l}\text { Annual 2008-13 } \\
\text { growth in: }\end{array}$} & (1) & $(2)$ & (3) & (4) & (5) & (6) & (7) & (8) & (9) \\
\hline & \multicolumn{3}{|c|}{ Employment } & \multicolumn{3}{|l|}{ Population } & \multicolumn{3}{|c|}{ House price per sqm } \\
\hline \multirow{2}{*}{$\begin{array}{l}\text { In(annual per capita } \\
\text { payments) }\end{array}$} & 0.0028 & 0.0010 & 0.0014 & $-0.0004^{* *}$ & -0.0000 & -0.0003 & $0.0063^{* *}$ & 0.0012 & 0.0029 \\
\hline & $(0.0017)$ & $(0.0017)$ & $(0.0014)$ & $(0.0002)$ & $(0.0002)$ & $(0.0002)$ & $(0.0025)$ & $(0.0020)$ & $(0.0021)$ \\
\hline \multicolumn{10}{|l|}{$\begin{array}{l}\text { Controls selected by the } \\
\text { double selection procedure: }\end{array}$} \\
\hline \multirow{2}{*}{$\begin{array}{l}\text { In(allocated per capita } \\
\text { funds) }\end{array}$} & & -0.0756 & $-0.0034^{* *}$ & & -0.0052 & 0.0002 & & $0.2453^{* * *}$ & 0.0034 \\
\hline & & $(0.0879)$ & $(0.0014)$ & & $(0.0116)$ & $(0.0003)$ & & $(0.0929)$ & $(0.0026)$ \\
\hline \multirow{2}{*}{$\begin{array}{l}\text { fraction of surface } \\
\text { composed of municipalities } \\
\text { on the coast }\end{array}$} & & -0.0015 & & & -0.0004 & $0.0010^{*}$ & & 0.0183 & \\
\hline & & $(0.0152)$ & & & $(0.0019)$ & $(0.0006)$ & & $(0.0172)$ & \\
\hline \multirow{2}{*}{$\begin{array}{l}\text { fraction of surface composed } \\
\text { of municipalities in a } \\
\text { mountain area }\end{array}$} & & -0.0084 & & & 0.00132 & & & $0.0300^{*}$ & $0.0055^{*}$ \\
\hline & & $(0.0131)$ & & & $(0.0017)$ & & & $(0.0157)$ & $(0.0031)$ \\
\hline \multirow[t]{2}{*}{ unemployment rate 2006} & & $-7.5712^{* *}$ & & & -0.0243 & & & $-5.4767^{*}$ & $-0.1442^{* * *}$ \\
\hline & & (3.5826) & & & $(0.3705)$ & & & $(3.2750)$ & $(0.0524)$ \\
\hline \multirow[t]{2}{*}{ In(employment) 2006} & & 2.0891 & & & 0.1027 & $0.0008^{* * *}$ & & 1.0234 & \\
\hline & & $(1.2758)$ & & & $(0.2218)$ & $(0.0002)$ & & $(1.4014)$ & \\
\hline \multirow[t]{2}{*}{ population growth 2004-07 } & & -1.7737 & $0.2652^{* * *}$ & & 0.6807 & $0.2124^{* * *}$ & & 1.2108 & \\
\hline & & $(2.7249)$ & $(0.0278)$ & & $(0.4949)$ & $(0.0109)$ & & $(4.6594)$ & \\
\hline \multirow[t]{2}{*}{ house price growth 2004-07 } & & 0.0881 & & & -0.0170 & $0.0022^{* *}$ & & $-0.6140^{* * *}$ & \\
\hline & & $(0.1615)$ & & & $(0.0201)$ & $(0.0010)$ & & $(0.1818)$ & \\
\hline \multirow{2}{*}{$\begin{array}{l}\text { share trade services workers } \\
2007\end{array}$} & & -0.0980 & & & -0.0002 & $0.0084^{* * *}$ & & $0.1629^{* *}$ & \\
\hline & & $(0.0658)$ & & & $(0.0081)$ & $(0.0026)$ & & $(0.0636)$ & \\
\hline \multirow[t]{2}{*}{ housing units $\mathrm{pc} \times$ time $^{2}$} & & -0.0124 & & & 0.0016 & & & -0.0009 & $0.0008^{* * *}$ \\
\hline & & $(0.0212)$ & & & $(0.0030)$ & & & (0.0198) & $(0.0002)$ \\
\hline
\end{tabular}


Table 2 The effects of European Structural Funds on annual growth, controlling for LLM time invariant characteristics and differential time trends (Continued)

\begin{tabular}{|c|c|c|c|c|c|c|c|c|c|}
\hline \multirow{2}{*}{$\begin{array}{l}\text { unemployment rate }{ }_{2006} \times \\
\text { time }\end{array}$} & & \multicolumn{3}{|l|}{$14.0820^{* * *}$} & \multicolumn{3}{|l|}{0.1115} & 6.8283 & $0.0469^{* * *}$ \\
\hline & & \multicolumn{3}{|l|}{ (4.9298) } & \multicolumn{3}{|l|}{$(0.5247)$} & (4.4299) & $(0.0095)$ \\
\hline \multirow{2}{*}{\multicolumn{2}{|c|}{$\begin{array}{l}\text { In(house price } \\
\text { per sqm) }{ }_{2006} \times \text { time }\end{array}$}} & \multicolumn{3}{|l|}{0.0694} & \multicolumn{3}{|l|}{-0.0036} & $0.2550^{* * *}$ & $-0.0061^{* * *}$ \\
\hline & & \multicolumn{3}{|l|}{$(0.0620)$} & \multicolumn{3}{|l|}{ (0.0079) } & $(0.0774)$ & $(0.0007)$ \\
\hline Additional controls & LLM FE & $\begin{array}{l}\text { All remaining } \\
\text { variables in } \\
f_{i}^{\prime} ; f_{i}^{\prime} \times t_{;} f_{i}^{\prime} \times t^{2}\end{array}$ & $\begin{array}{l}\text { No additional } \\
\text { controls }\end{array}$ & LLM FE & $\begin{array}{l}\text { All remaining } \\
\text { variables in } \\
f_{i}^{\prime} ; f_{i}^{\prime} \times t_{i} f_{i}^{\prime} \times t^{2}\end{array}$ & $\begin{array}{l}\text { No additional } \\
\text { controls }\end{array}$ & LLM FE & $\begin{array}{l}\text { All remaining } \\
\text { variables in } \\
f_{i}^{\prime} ; f_{i}^{\prime} \times t_{;} f_{i}^{\prime} \times t^{2}\end{array}$ & $\begin{array}{l}\text { No additional } \\
\text { controls }\end{array}$ \\
\hline Obs & 1950 & 1950 & 1950 & 1950 & 1950 & 1950 & 1950 & 1950 & 1950 \\
\hline R2 & 0.2350 & 0.3403 & 0.2354 & 0.1519 & 0.6745 & 0.5934 & 0.3302 & 0.5170 & 0.3074 \\
\hline Strict exog test & 0.2892 & & & 0.6070 & & & & 0.1941 & \\
\hline
\end{tabular}

Note:

The regressions include a constant and year fixed effects. Standard errors clustered for LLM in parentheses. See Table 1 for data sources. $f_{i}^{\prime}$ is a vector of pre-determined covariates: the employment rate, unemployment rate, activity rate, and level of the outcomes (in logarithm) for 2004, 2005, 2006 and 2007; the growth of the outcomes over 2004-07; total surface (in kmq), population density in 2007, average altitude, fraction of surface composed of municipalities in a mountain area, fraction composed of municipalities located on the coast, total number of houses per capita (census 2001 on population 2007) and total number of empty houses per capita (census 2001 on population 2007); 2007 share of private workers in construction, trade services, and other services (considering manufacturing as the excluded category); logarithm of originally allocated funds (and its square). Columns (1), (4), (7) include only LLM FE, with no additional controls. Controls in columns (3), (6), (9) have been selected using the "double selection" of Belloni et al. (2014) and the code provided by the authors. Columns (2), (5), (8) include all $f_{i}$, $f_{i}^{\prime} \times t$ and $f_{i}^{\prime} \times t^{2}$, but only coefficients on those that are also "double selected" are shown (a full regression table is available from the authors). The strict exogeneity test is the $p$-value for a test for $\mathrm{H}_{0}: \ln (\text { annual } p c \text { payments })_{t+1}=0$

${ }^{*} p<.10{ }^{* *} p<.05{ }^{* *} p<.01$ 
Table 3 The effects of European Structural Funds on average 2008-13 growth, controlling for LLM time invariant characteristics

\begin{tabular}{|c|c|c|c|c|c|c|}
\hline & (1) & (2) & (3) & (4) & (5) & (6) \\
\hline & \multicolumn{6}{|c|}{ Average 2008-2013 growth in: } \\
\hline & \multicolumn{2}{|c|}{ Employment } & \multicolumn{2}{|l|}{ Population } & \multicolumn{2}{|c|}{ House price per sqm } \\
\hline \multirow{2}{*}{$\begin{array}{l}\text { In(cumulative pc payments } \\
\text { 07-13) }\end{array}$} & -0.0001 & -0.0035 & 0.0002 & -0.0002 & $-0.0118^{* *}$ & $-0.0093^{* *}$ \\
\hline & $(0.0026)$ & $(0.0026)$ & $(0.0007)$ & $(0.0007)$ & $(0.0049)$ & $(0.0044)$ \\
\hline \multicolumn{7}{|c|}{ Controls selected by the double selection procedure: } \\
\hline \multirow[t]{2}{*}{ In(allocated per capita funds) } & -0.0156 & 0.0003 & 0.0021 & 0.0004 & 0.0124 & $0.0072^{* *}$ \\
\hline & $(0.0126)$ & $(0.0021)$ & $(0.0038)$ & $(0.0006)$ & $(0.0293)$ & $(0.0032)$ \\
\hline \multirow{2}{*}{$\begin{array}{l}\text { fraction of surface composed } \\
\text { of municipalities on the coast }\end{array}$} & -0.0017 & & 0.0004 & $0.0017^{* * *}$ & $0.0112^{* *}$ & \\
\hline & $(0.0022)$ & & $(0.0007)$ & $(0.0005)$ & $(0.0049)$ & \\
\hline \multirow[t]{2}{*}{ In(house price per sqm) 2005} & $0.0541^{* * *}$ & $0.0051^{* * *}$ & 0.0001 & & 0.0149 & \\
\hline & $(0.0182)$ & $(0.0016)$ & $(0.0054)$ & & $(0.0309)$ & \\
\hline \multirow[t]{2}{*}{ In(employment $)_{2006}$} & 0.1356 & & -0.0471 & $0.0005^{* * *}$ & $1.6895^{* * *}$ & \\
\hline & $(0.2104)$ & & $(0.0549)$ & $(0.0002)$ & $(0.3555)$ & \\
\hline \multirow[t]{2}{*}{ In(house price per sqm) 2006} & 0.0012 & & 0.0012 & & $-0.1604^{* * *}$ & $-0.0186^{* * *}$ \\
\hline & $(0.0158)$ & & $(0.0051)$ & & $(0.0334)$ & $(0.0035)$ \\
\hline \multirow[t]{2}{*}{ In(house price per sqm) 2007} & $-0.0664^{* *}$ & & $0.0257^{* * *}$ & 0.0008 & 0.0241 & \\
\hline & $(0.0284)$ & & $(0.0083)$ & $(0.0005)$ & $(0.0915)$ & \\
\hline \multirow[t]{2}{*}{ population growth 2004-07 } & -0.3647 & $0.2179^{* * *}$ & 0.0946 & $0.2158^{* * *}$ & -0.4706 & \\
\hline & $(1.3937)$ & $(0.0323)$ & $(0.4192)$ & $(0.0106)$ & (3.0035) & \\
\hline Additional controls & $\begin{array}{l}\text { All } \\
\text { remaining } \\
\text { vars in } f_{i}^{\prime}\end{array}$ & $\begin{array}{l}\text { No } \\
\text { additional } \\
\text { controls }\end{array}$ & $\begin{array}{l}\text { All remaining } \\
\text { vars in } f_{i}^{\prime}\end{array}$ & $\begin{array}{l}\text { No additional } \\
\text { controls }\end{array}$ & $\begin{array}{l}\text { All remaining } \\
\text { vars in } f_{i}^{\prime}\end{array}$ & $\begin{array}{l}\text { No additional } \\
\text { controls }\end{array}$ \\
\hline Obs & 325 & 325 & 325 & 325 & 325 & 325 \\
\hline R2 & 0.5031 & 0.2719 & 0.8396 & 0.7771 & 0.4836 & 0.1145 \\
\hline
\end{tabular}

Note:

The unit of observation is the LLM over time. See Table 1 for data sources. The regressions include a constant. Robust standard errors in parentheses. The average growth over 2008-13 is calculated as a geometric average. See Table 2 for the full list of covariates. Controls in columns (2), (4), (6) have been selected using the "double selection" of Belloni et al. (2014) and the code provided by the authors. Columns (1), (3), (5) include all $f_{i}^{\prime}$, but only coefficients on those that are also "double selected" are shown (full regressions table are available from the authors) ${ }^{*} p<.10 * * p<.05 * * * p<.01$

One concern is that, in 2007-08, the EU funding referring to the previous (2000-06) programing period have also been disbursed because of the $\mathrm{n}+2$ rule (according to which the allocated money should be spent within two years of the budgeting). Disbursements referring to the 2000-06 programing period are not registered in OpenCoesione. Therefore, failing to account for this financing might impair our ability to detect an effect for the 2007-14 funding as we have two years in which payments overlap. To account for this, we shorten our estimation window by excluding the growth in years 2008 and 2009. Results (available upon request) referring to this period are very similar to those depicted in Tables 2 and 3. The main exception refers to a statistically significant and positive effect on employment in the year-to-year specifications only, with an economic magnitude, however, very close to zero. This effect is similar to the small positive effects in 2010-11 and 2011-12 that we find when we focus on single couples of years (see section 7.2) and when we include lags of the explanatory variable (which forces us to exclude the first two years; see section 7.8). 
Even if there is no evidence of significant effects on the average, funds might have attenuated the impact of the recession on the most vulnerable LLMs. In this case, we expect that payments had an effect on the lowest percentiles of the distribution of growth rates in the outcomes. We run quantile regressions for the $25^{\text {th }}$ and $75^{\text {th }}$ percentiles of the distribution, both without any covariates and with those that were retained after "double selection". Results are in line with those referring to the average and discussed in the text.

Finally, the choice of outcomes may be debatable. Private employment can be affected more by these transfers. Similarly, population mobility is typically stronger for younger individuals. We also estimated the main regressions (Tables 1-3) using as the outcome the growth in the private employment in plants located in the area from the Istat Statistical Archive on Active Enterprises (an annual census of the private sector). Data are currently available only up to the year 2012. Results for the average 2007-2012 growth show no effect of the EU transfers. Estimates for annual growth are statistically significant, but only when we include the long list of covariates, and they are anyway small in economic terms: around $0.07 \%$ increase in employment with a $10 \%$ increase in per capita payments (similar to other results found for specific years; see Section 7.2). We also re-estimated the main regressions using the population between 25 and 34 years of age. The empirical relation turns out to be negative, but never larger (across the different methods) than a $0.10 \%$ decrease with a $10 \%$ increase in per capita payments. Similar results, negative but smaller in size, hold for the age classes $25-44$ and $15-64$.

\subsection{Did the 2011 "Piano di Azione e Coesione" have any effect?}

As explained in Section 4, in 2011 a number of actions were taken to ensure faster spending and a re-focusing of the existent programs towards counter-cyclical aims. To inspect whether these actions had any impulse on the effectiveness of funds, we replicated the regressions for annual growth by selecting couples of annual growth rates (to have specifications that still allow us to include LLM fixed-effects).

With respect to employment (Table 4), the OLS results (first row) show small effects that are hardly statistically significant. The FE results (second row) uncover a stronger and statistically significant effect in 2012-13 and a positive one in 2011-12, but not statistically significant. When we use (third row) fixed covariates and their interaction with the time trend (captured by a second year dummy specific to each subsample), we find a positive effect in 2010-11 and 2011-12, around 0.07\% increase in employment with a 10\% increase in per capita payments. In this specification, payments seemed to have had a negative effect on employment in 2008-09. The estimates obtained by using the Belloni et al. (2014) selection procedure (fourth row) are very similar to those obtained with the full set of $f_{i}^{\prime}$ variables (the tables with the estimates for the covariates are available in the Additional file 1). The estimated impact on employment between 2010 and 2012 is not strong, but not negligible. In those years, the average per-capita payment across the LLMs was 143 euros, with an average population of 63,000 and an average total employment of 19,000. This implies that an increase by $10 \%$ in the expenditure for the average LLM would have increased its employment by approximately 13 units. Calculating the total increase in expenditure at the average population (14.3 times 63,000), the cost per additional unit of employment would have been around 68,000 euros. The variability of per capita payments was actually quite high in those years, so it is interesting to evaluate the 
Table 4 The effects of European Structural Funds on annual growth in employment

\begin{tabular}{|c|c|c|c|c|c|c|}
\hline \multirow{2}{*}{$\begin{array}{l}\text { Dep. var:: annual growth in } \\
\text { employment }\end{array}$} & \multirow{2}{*}{$\begin{array}{l}1) \\
2008-09\end{array}$} & \multirow{2}{*}{$\begin{array}{l}\text { (2) } \\
2009-10\end{array}$} & \multirow{2}{*}{$\begin{array}{l}(3) \\
2010-11\end{array}$} & \multirow{2}{*}{$\begin{array}{l}\text { (4) } \\
2011-12\end{array}$} & \multirow{2}{*}{$\begin{array}{l}5) \\
2012-13\end{array}$} & \multirow{2}{*}{$\begin{array}{l}\text { Test for (1)-(5) } \\
\text { jointly zero ( } p \text {-val) }\end{array}$} \\
\hline & & & & & & \\
\hline & OLS & & & & & \\
\hline \multirow[t]{3}{*}{ In(annual per capita payments) $)_{t}$} & -0.0009 & $0.0031^{*}$ & -0.0023 & 0.0002 & $0.0041^{*}$ & 0.0034 \\
\hline & $(0.0014)$ & $(0.0017)$ & $(0.0024)$ & $(0.0022)$ & $(0.0023)$ & \\
\hline & LLM FE & & & & & \\
\hline \multirow[t]{3}{*}{ In(annual per capita payments) } & -0.0045 & 0.0035 & 0.0042 & 0.0121 & $0.0212^{* * *}$ & 0.0742 \\
\hline & $(0.0041)$ & $(0.0051)$ & $(0.0056)$ & $(0.0083)$ & $(0.0074)$ & \\
\hline & \multicolumn{5}{|c|}{ With $f_{i}^{\prime}$ and $f_{i}^{\prime} \times 1$ [second year $]$} & \\
\hline \multirow[t]{3}{*}{ In(annual per capita payments) $)_{t}$} & $-0.0034^{*}$ & 0.0016 & $0.0069^{* *}$ & $0.0079^{* *}$ & 0.0024 & 0.0250 \\
\hline & $(0.0019)$ & $(0.0026)$ & $(0.0029)$ & $(0.0038)$ & $(0.0032)$ & \\
\hline & \multicolumn{5}{|c|}{ With selected covariates (double selection) } & \\
\hline \multirow[t]{2}{*}{ In(annual per capita payments) $)_{t}$} & $-0.0043^{* *}$ & 0.0014 & $0.0074^{* *}$ & $0.0067^{*}$ & 0.0049 & 0.0291 \\
\hline & $(0.0019)$ & $(0.0026)$ & $(0.0032)$ & $(0.0038)$ & $(0.0034)$ & \\
\hline Obs & 650 & 650 & 650 & 650 & 650 & \\
\hline
\end{tabular}

Note:

Standard errors clustered for LLM in parentheses. See Tables 1-2 for other info. The "double selection" has been conducted separately for each couple of years. See Additional file 1: Table S3 for the coefficients on these variables ${ }^{*} p<.10{ }^{* *} p<.05{ }^{* * *} p<.01$

effect of one standard deviation increase in the per capita payments (approximately 100 euros, around $70 \%$ of the average). This would imply an increase in employment by around $0.37 \%$, which is 70 units if evaluated at the average. ${ }^{8}$ Overall, the acceleration/ retargeting of the payments that started in 2011 seemed to have caused a modest rise in employment (which however loses momentum starting from 2012).

If we focus on population (Table 5), there is no difference with our previous results, pointing to an overall ineffectiveness. OLS uncover some relations, but all other estimates are neither statistically, nor economically significant. With respect to house

Table 5 The effects of European Structural Funds on annual growth in population

\begin{tabular}{|c|c|c|c|c|c|c|}
\hline \multirow{2}{*}{$\begin{array}{l}\text { Dep. var.: annual growth in } \\
\text { population }\end{array}$} & \multirow{2}{*}{$\begin{array}{l}(1) \\
2008-09\end{array}$} & \multirow{2}{*}{$\begin{array}{l}\text { (2) } \\
2009-10\end{array}$} & \multirow{2}{*}{$\begin{array}{l}\text { (3) } \\
\text { 2010-11 }\end{array}$} & \multirow{2}{*}{$\begin{array}{l}\text { (4) } \\
2011-12\end{array}$} & \multirow{2}{*}{$\begin{array}{l}\text { (5) } \\
2012-13\end{array}$} & \multirow{2}{*}{$\begin{array}{l}\text { Test for (1)-(5) } \\
\text { jointly zero ( } p \text {-val) }\end{array}$} \\
\hline & & & & & & \\
\hline & OLS & & & & & \\
\hline \multirow[t]{3}{*}{ In(annual per capita payments) ${ }_{t}$} & -0.0002 & 0.0003 & $0.0014^{* *}$ & $0.0012^{* *}$ & $0.0011^{* *}$ & 0.0082 \\
\hline & $(0.0004)$ & $(0.0004)$ & $(0.0005)$ & $(0.0005)$ & $(0.0005)$ & \\
\hline & LLM FE & & & & & \\
\hline \multirow[t]{3}{*}{ In(annual per capita payments)t } & -0.0004 & -0.0002 & -0.0003 & 0.0000 & 0.0014 & 0.5489 \\
\hline & $(0.0004)$ & $(0.0005)$ & $(0.0005)$ & $(0.0006)$ & $(0.0010)$ & \\
\hline & \multicolumn{5}{|c|}{ With $f_{i}^{\prime}$ and $f_{i}^{\prime} \times 1[$ sec ond year $]$} & \\
\hline \multirow[t]{3}{*}{ In(annual per capita payments) ${ }_{t}$} & -0.0003 & -0.0001 & 0.0002 & 0.0002 & 0.0004 & 0.7046 \\
\hline & $(0.0003)$ & $(0.0004)$ & $(0.0004)$ & $(0.0006)$ & $(0.0005)$ & \\
\hline & \multicolumn{5}{|c|}{ With selected covariates (double selection) } & \\
\hline \multirow[t]{2}{*}{ In(annual per capita payments) } & $-0.0005^{*}$ & 0.0001 & 0.0001 & -0.0000 & 0.0003 & 0.3452 \\
\hline & $(0.0003)$ & $(0.0004)$ & $(0.0004)$ & $(0.0005)$ & $(0.0005)$ & \\
\hline Obs & 650 & 650 & 650 & 650 & 650 & \\
\hline
\end{tabular}

Note:

Standard errors clustered for LLM in parentheses. See Tables 1-2 for other info. The "double selection" has been conducted separately for each couple of years. See Additional file 1: Table S4 for the coefficients on these variables ${ }^{*} p<.10{ }^{* *} p<.05{ }^{* * *} p<.01$ 
Table 6 The effects of European Structural Funds on annual growth in house prices

\begin{tabular}{|c|c|c|c|c|c|c|}
\hline \multirow{2}{*}{$\begin{array}{l}\text { Dep. var.: annual growth in } \\
\text { house price per sqm }\end{array}$} & (1) & (2) & (3) & (4) & (5) & \multirow{2}{*}{$\begin{array}{l}\text { Test for (1)-(5) } \\
\text { jointly zero ( } p \text {-val) }\end{array}$} \\
\hline & 2008-09 & 2009-10 & 2010-11 & 2011-12 & 2012-13 & \\
\hline & \multicolumn{6}{|l|}{ OLS } \\
\hline \multirow[t]{3}{*}{ In(annual per capita payments) $)_{t}$} & $0.0037^{*}$ & $0.0054^{* * *}$ & -0.0006 & -0.0030 & $-0.0081^{* * *}$ & \multirow[t]{3}{*}{0.0000} \\
\hline & $(0.0022)$ & $(0.0016)$ & $(0.0030)$ & $(0.0022)$ & $(0.0022)$ & \\
\hline & LLM FE & & & & & \\
\hline \multirow[t]{3}{*}{ In(annual per capita payments) $)_{t}$} & 0.0032 & $0.0285^{* * *}$ & -0.0017 & 0.0042 & -0.0026 & \multirow[t]{2}{*}{0.0025} \\
\hline & $(0.0039)$ & $(0.0075)$ & $(0.0042)$ & $(0.0046)$ & $(0.0031)$ & \\
\hline & \multicolumn{6}{|c|}{ With $f_{i}^{\prime}$ and $f_{i}^{\prime} \times 1$ second year $]$} \\
\hline \multirow[t]{3}{*}{ In(annual per capita payments) $)_{t}$} & -0.0022 & 0.0022 & 0.0020 & -0.0034 & $-0.0066^{*}$ & \multirow[t]{2}{*}{0.3003} \\
\hline & $(0.0032)$ & $(0.0029)$ & $(0.0041)$ & $(0.0034)$ & $(0.0037)$ & \\
\hline & \multicolumn{6}{|c|}{ With selected covariates (double selection) } \\
\hline \multirow[t]{2}{*}{ In(annual per capita payments) $)_{t}$} & 0.0034 & $0.0118^{* * *}$ & $0.0068^{*}$ & -0.0030 & $-0.0065^{*}$ & \multirow[t]{2}{*}{0.0143} \\
\hline & $(0.0030)$ & $(0.0037)$ & $(0.0037)$ & $(0.0033)$ & $(0.0034)$ & \\
\hline Obs & 650 & 650 & 650 & 650 & 650 & \\
\hline
\end{tabular}

prices (Table 6), results seem to suggest a positive effect in 2009-10 and a negative one (but statistically significant only at the 10\% level) in 2012-13. The effect in 2009-10 is recovered when we use only selected covariates, but it actually disappears (without a decrease in the precision of the estimates) when we include the full set of covariates and interactions with the time trend. ${ }^{9}$

\subsection{Is there any difference according to the type of programs?}

Projects funded by EU Structural Funds are heterogeneous. Broadly speaking, they refer to four categories: (i) payments for the purchase of goods and services; (ii) incentives for firms and workers; (iii) payments for infrastructural projects; and (iv) other expenditures (purchase of stocks or other capital transfers). For the first category, during each year between 2008 and 2013, there were positive payments in all LLMs, although 9.5\% of the LLMs had payments smaller than one euro per-capita in 2008. Payments related to incentives were 0 only in $4.3 \%$ of the LLM-year observations (concentrated in 2008, where they represented the $24.3 \%$ ), with an additional $3.2 \%$ smaller than one euro per-capita. Payments for infrastructures were 0 in $6.9 \%$ of the cases, while they were negative (due to reimbursements relative to projects that had been stopped) only for $1.1 \%$ of the observations. An additional 9.9\% were smaller than one euro per-capita. In all these cases we impose the log to be equal to zero. We ignore the last category (other expenditures) because it amounted to $2.8 \%$ of total cumulative payments in 2013, with the majority of LLM-year observations equal to 0 .

In Table 7 we estimate the impact of the different kinds of expenditures by replicating the year-to-year specifications of Table 2. Fixed-effect estimates suggest a small but positive effect of purchase of goods and services and incentives on employment (Column 1). For the payments relative to the purchase of goods and services there is evidence that the strict exogeneity condition required for fixed effects to be consistent is violated. Nevertheless, positive though smaller impacts are uncovered also through 
Table 7 The effects of European Structural Funds on annual growth, 2008-13. Heterogeneity with respect to the kind of payments

\begin{tabular}{|c|c|c|c|c|c|c|c|c|c|}
\hline \multirow{2}{*}{ Annual 2008-13 growth in: } & (1) & (2) & (3) & (4) & (5) & (6) & (7) & (8) & (9) \\
\hline & \multicolumn{3}{|c|}{ Employment } & \multicolumn{3}{|l|}{ Population } & \multicolumn{3}{|c|}{ House price per sqm } \\
\hline \multirow{2}{*}{$\begin{array}{l}\text { In(annual pc payments for } \\
\text { goods and services purchase)t }\end{array}$} & $0.0062^{* * *}$ & $0.0047^{* * *}$ & $0.0031^{* *}$ & $-0.0008^{* * *}$ & -0.0002 & 0.0000 & 0.0044 & 0.0030 & 0.0024 \\
\hline & $(0.0021)$ & $(0.0017)$ & $(0.0015)$ & $(0.0002)$ & $(0.0002)$ & $(0.0002)$ & $(0.0029)$ & $(0.0021)$ & $(0.0021)$ \\
\hline \multirow{2}{*}{$\begin{array}{l}\text { In(annual pc payments for } \\
\text { ncentives) })_{t}\end{array}$} & $0.0032^{* * *}$ & $0.0020^{*}$ & $0.0027^{* * *}$ & -0.0000 & -0.0002 & $-0.0003^{*}$ & 0.0007 & 0.0013 & 0.0000 \\
\hline & $(0.0012)$ & $(0.0011)$ & $(0.0010)$ & $(0.0001)$ & $(0.0001)$ & $(0.0001)$ & $(0.0015)$ & $(0.0011)$ & $(0.0013)$ \\
\hline \multirow{2}{*}{$\begin{array}{l}\text { In(annual pc payments for } \\
\text { infrastructural projects) }\end{array}$} & 0.0000 & 0.0009 & 0.0002 & -0.0001 & 0.0000 & -0.0000 & 0.0013 & $-0.0012^{*}$ & -0.0004 \\
\hline & $(0.0007)$ & $(0.0005)$ & $(0.0005)$ & $(0.0001)$ & $(0.0001)$ & $(0.0001)$ & $(0.0009)$ & $(0.0007)$ & $(0.0007)$ \\
\hline \multirow[t]{3}{*}{ Additional controls } & & All $f_{i}^{\prime} ;$ & Chosen by double & & All $f_{i}^{\prime} ;$ & Chosen by double & & All $f_{i}^{\prime} ;$ & Chosen by double \\
\hline & & $f_{i}^{\prime} \times t_{i}$ & & & $f_{i}^{\prime} \times t_{i}$ & & & $f_{i}^{\prime} \times t_{i}$ & \\
\hline & LLM FE & $f_{i}^{\prime} \times t^{2}$ & & LLM FE & $f_{i}^{\prime} \times t^{2}$ & & LLM FE & $f_{i}^{\prime} \times t^{2}$ & \\
\hline Obs & 1950 & 1950 & 1950 & 1950 & 1950 & 1950 & 1950 & 1950 & 1950 \\
\hline R2 & 0.2420 & 0.3452 & 0.2471 & 0.1566 & 0.6751 & 0.6093 & 0.3284 & 0.5191 & 0.3418 \\
\hline \multicolumn{10}{|l|}{ Strict exog test for: } \\
\hline - Goods and services & 0.0005 & & & 0.0934 & & & 0.0006 & & \\
\hline - Incentives & 0.2651 & & & 0.5723 & & & 0.2803 & & \\
\hline - Infrastructural projects & 0.9358 & & & 0.9287 & & & 0.0364 & & \\
\hline
\end{tabular}

Standard errors clustered for LLM in parentheses. See Tables $1-2$ for other info. The strict exogeneity test is the $p$-value for a test for $\mathrm{H}_{0}: \operatorname{In}\left(\right.$ annual payment for $\ldots$...) $t_{t+1}=0$. Columns (1), (4), (7) include only LLM FE, with no additional controls. Controls in column (3), (6), (9) have been selected using the "double selection" of Belloni et al. (2014) and the code provided by the authors ${ }^{*} p<.10 * * p<.05 * * * p<.01$ 
the estimation that uses fixed time covariates and interactions with the time trend (Columns 2 and 3). On the other hand, the payments related to infrastructural projects do not show any impact on local employment. The results referring to the population and house prices growth (from Column 4 to Column 9) do not signal any interesting pattern attributable to the different types of projects.

One possible reason for the positive effect associated with the first two categories of spending is that their impact is more likely to be found over a short-term period. This could be particularly true for some categories of incentives that address the crisisinduced difficulties of the firms, such as wage-supplementation schemes and public credit guarantees. Differently, infrastructure is more likely to impact over the longer run and therefore its effect may not be detected by our analysis. Moreover, disbursements referred to infrastructures generally pre-date the moment in which the public goods are completed (so to trigger economic effects on our outcomes).

Given that the logarithm of infrastructural spending displays a large mass of yearLLM observation at zero, we also tried to run the regressions looking at the effect of the cumulate 2007-13 spending on the average growth during the period (similarly to Table 3). In this case, all LLMs have positive payments (larger than one euro per capita) for the three kinds of spending. For infrastructural projects, these regressions (available on request) still display close to zero coefficients for the effects on employment and population, and a negative one on house prices $(0.05 \%$ decrease with a $10 \%$ increase in payments). As could be expected, in this case also the other two categories of spending show no relation with the outcomes, probably because the short term effect on employment is hardly captured without properly modeling the underlying annual trends. Only population appears to be slightly positively affected by the purchase of goods and services.

\subsection{Slackness in housing and labor market}

A standard spatial equilibrium model, as in Kline and Moretti (2013a), suggests that the effect on population mobility and house prices depends on the elasticity of local labor and housing supply. For instance, in a scenario of low employment, additional labor demand generated by transfers may increase the local employment rate without attracting population from other areas. Real estate prices are also more likely to change if there is a shortage of housing supply, so that the increase in income and/or population will increase rents. We broadly test whether the implications of the spatial equilibrium model apply in our data by constructing two simple indicators of labor and housing market slackness. The first is a dummy variable for the lowest quintile of employment rate in 2007, which should capture those areas that have a larger availability of potential labor supply. The second is an indicator for the lowest quintile of housing prices in 2007, which should capture the availability of affordable housing.

Table 8 shows the results from regressions for annual growth that also include interactions between the flow of payments and the indicators for slackness in housing and labor market (plus the main effect of these two variables in regressions without FE). We fail to find any evidence of a differential effect on employment (Columns 1-3). When using fixed effects (Column 4) or "double selected" LLM characteristics (Column 6), population seems to be negatively affected on average, but the presence of affordable 
Table 8 The effects of European Structural Funds on annual growth, 2008-13. Heterogeneity with respect to slackness in the housing and labor markets

\begin{tabular}{|c|c|c|c|c|c|c|c|c|c|}
\hline \multirow{2}{*}{$\begin{array}{l}\text { Annual 2008-13 growth } \\
\text { in: }\end{array}$} & (1) & (2) & (3) & (4) & (5) & (6) & (7) & (8) & (9) \\
\hline & \multicolumn{3}{|c|}{ Employment } & \multicolumn{3}{|l|}{ Population } & \multicolumn{3}{|c|}{ House price per sqm } \\
\hline \multirow[t]{2}{*}{ In(annual pc payments) $)_{t}$} & 0.0027 & -0.0008 & 0.0010 & $-0.0006^{* * *}$ & -0.0001 & $-0.0005^{* *}$ & $0.0064^{* *}$ & 0.0021 & 0.0035 \\
\hline & $(0.0020)$ & $(0.0020)$ & $(0.0016)$ & $(0.0002)$ & $(0.0003)$ & $(0.0002)$ & $(0.0027)$ & $(0.0022)$ & $(0.0022)$ \\
\hline \multirow{2}{*}{$\begin{array}{l}\text { In(annual pc payments) })_{t} \times \\
\text { housing slack indicator }\end{array}$} & 0.0012 & 0.0032 & 0.0020 & $0.0005^{*}$ & 0.0004 & $0.0007^{* *}$ & $-0.0066^{*}$ & -0.0022 & $-0.0064^{*}$ \\
\hline & $(0.0025)$ & $(0.0022)$ & $(0.0021)$ & $(0.0003)$ & $(0.0004)$ & $(0.0003)$ & $(0.0036)$ & $(0.0031)$ & $(0.0034)$ \\
\hline \multirow{2}{*}{$\begin{array}{l}\text { In(annual pc payments) })_{t} \times \\
\text { labor mkt slack indicator }\end{array}$} & -0.0011 & $0.0049^{*}$ & -0.0007 & 0.0002 & -0.0002 & 0.0000 & $0.0100^{* * *}$ & -0.0007 & $0.0076^{* *}$ \\
\hline & $(0.0027)$ & $(0.0028)$ & $(0.0022)$ & $(0.0003)$ & $(0.0004)$ & $(0.0004)$ & $(0.0033)$ & $(0.0027)$ & $(0.0030)$ \\
\hline \multirow[t]{2}{*}{ Housing slack indicator } & & -0.0150 & -0.0118 & & -0.0022 & $-0.0041^{* *}$ & & 0.0183 & $0.0381^{* *}$ \\
\hline & & $(0.0100)$ & $(0.0095)$ & & $(0.0018)$ & $(0.0017)$ & & $(0.0142)$ & $(0.0155)$ \\
\hline \multirow[t]{2}{*}{ Labor mkt slack indicator } & & $-0.0214^{*}$ & 0.0057 & & 0.0026 & 0.0006 & & 0.0054 & $-0.0321^{* *}$ \\
\hline & & $(0.0126)$ & $(0.0099)$ & & $(0.0020)$ & $(0.0018)$ & & $(0.0129)$ & $(0.0142)$ \\
\hline \multirow[t]{3}{*}{ Additional controls } & LLM FE & All $f_{i}^{\prime} ;$ & $\begin{array}{l}\text { Chosen by double } \\
\text { selection }\end{array}$ & LLM FE & All $f_{i}^{\prime} ;$ & $\begin{array}{l}\text { Chosen by double } \\
\text { selection }\end{array}$ & LLM FE & All $f_{i}^{\prime} ;$ & $\begin{array}{l}\text { Chosen by double } \\
\text { x'selection }\end{array}$ \\
\hline & & $f_{i}^{\prime} \times t_{i}$ & & & $f_{i}^{\prime} \times t_{i}$ & & & $f_{i}^{\prime} \times t_{i}$ & \\
\hline & & $f_{i}^{\prime} \times t^{2}$ & & & $f_{i}^{\prime} \times t^{2}$ & & & $f_{i}^{\prime} \times t^{2}$ & \\
\hline Obs & 1950 & 1950 & 1950 & 1950 & 1950 & 1950 & 1950 & 1950 & 1950 \\
\hline R2 & 0.2352 & 0.3415 & 0.2366 & 0.1550 & 0.6771 & 0.5973 & 0.3368 & 0.5191 & 0.3167 \\
\hline
\end{tabular}

Note:

Standard errors clustered for LLM in parentheses. See Table 2 for other info. The housing slack indicator is a dummy for the lowest quintile of housing prices across all LLMs in 2007. The labor market slack is a dummy for the lowest quintile of employment rate in 2007. Columns (1), (4), (7) include only LLM FE, with no additional controls. To avoid introducing an additional source of variation, controls in columns (3), (6), (9) are the same selected for Table 2 
housing seems to compensate this effect (the results from controlling for the full set of $f_{i}^{\prime}$ variables are similar but not significant at the usual levels). The housing slackness (Columns 7-9) seems also to have a counteracting effect on the evolution of housing prices (but statistically significant only at the $10 \%$ level). Differently, the labor market slackness is associated with a positive effect of the European funds, which is a result that does not lend credit to the implications of the spatial equilibrium model.

\subsection{Faster disbursements?}

A recurring argument in the Italian policy debate on Structural Funds refers to the actual capacity of spending the available EU money. For instance, for Southern Italy, at the end of 2013, only roughly $50 \%$ of the resources available for the 2007-13 programing period was spent. A popular argument is that if local authorities would have been able to spend all the available EU money, then the economic consequences of the crisis could have been less dramatic. We have already highlighted that the acceleration of funding achieved with the "Piano di Azione and Coesione" may have had only a reduced impulse on employment starting from 2011. In this Section, we study whether those LLMs that have been able to spend the most of the allocated money have shown better performances compared with their less efficient counterparts.

To this purpose, in Table 9 we focus on the average growth 2008-13 and replace the variable of interest, which is taken now to be the fraction of available funds that have been spent by the end of $2013 .{ }^{10}$ The results are extremely similar to those we found in the baseline estimates of Table $3 .{ }^{11}$ It does not seem, therefore, that those LLM who spent a larger fraction of the available funding experienced higher effectiveness of the interventions.

\subsection{Interactions with national funding}

As discussed in Section 4, during 2007-13 there were also cohesion projects entirely funded by national sources. These concurrent programs are likely not going to make a difference for the estimated effectiveness of EU funding: they amount to $3.1 \%$ of the EU transfers we have considered up to now. In any case, in Table 10 we add per-capita payments relative to nationally-funded programs in the regressions. We focused on the average growth specification because these funds are more limited and therefore in some years they amount to zero for the vast majority of LLMs. ${ }^{12}$ On the whole period, the LLMs with less than one euro per-capita of expenditure from these funds are 43 (13\%; 11 LLMs have zero payments), and we recode their logarithm to zero. Results without this correction (excluding those with zero payments) and results for annual growth (imposing the logarithm to be zero) lead to similar conclusions and are available on request.

Table 10 shows that the expenditure related to national sources is unrelated to all three outcomes (apart from a marginally statistically and economically significant relation with employment found in Column 1). It is therefore not surprising that the estimated effects of the EU funds are extremely similar to the main estimates provided in Table 2.

\subsection{Absorptive capacity: heterogeneity by human capital}

Becker et al. (2013) find that regions characterized by lower human capital and/or quality of institutions are less able to reap the gains of European transfers, even if they 
Table 9 The effects of the usage of European Structural Funds on average 2008-13 growth, controlling for LLM time invariant characteristics

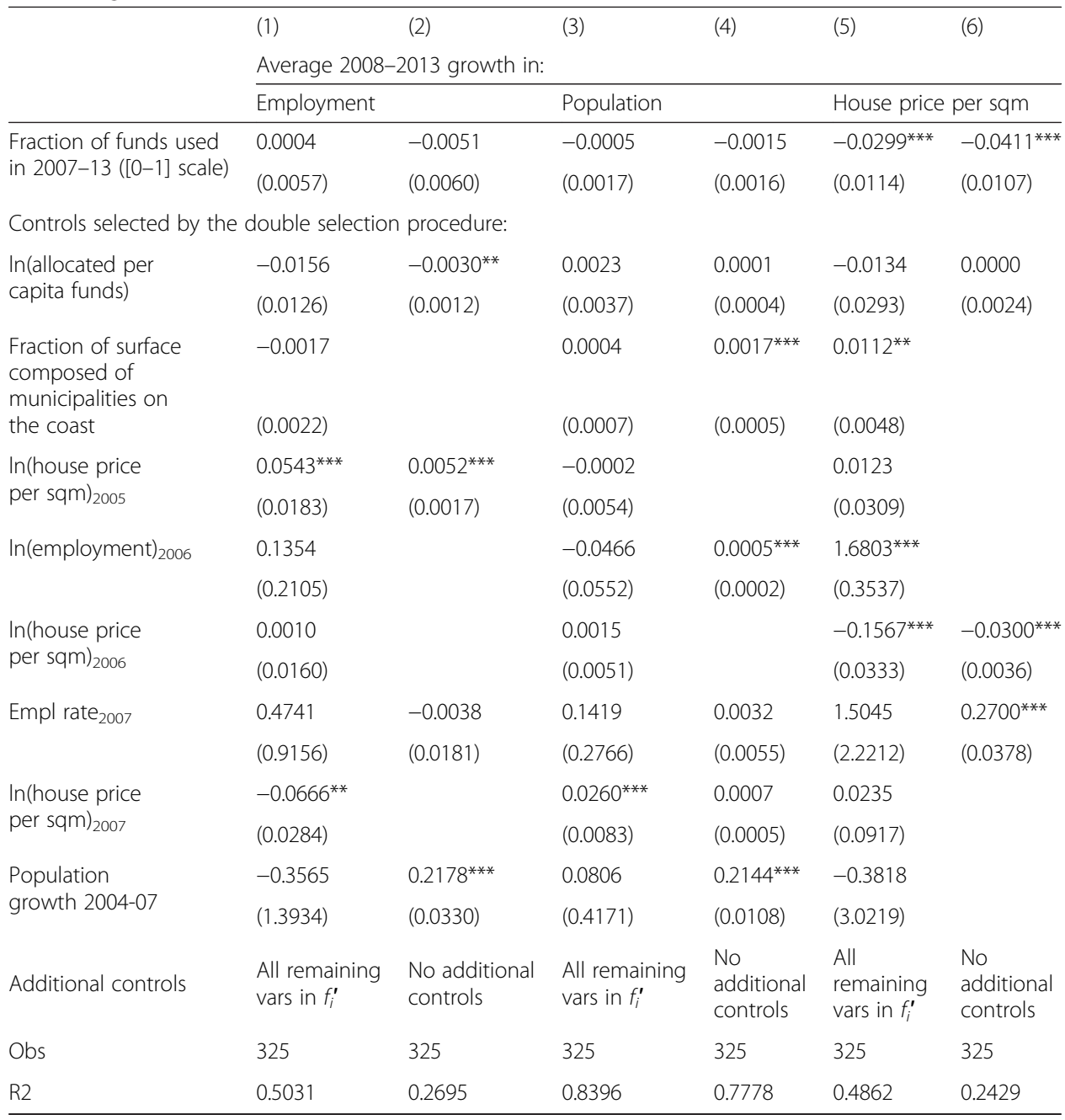

Note:

The unit of observation is the LLM over time. See Table 1 for data sources. The regressions include a constant. Robust standard errors in parentheses. The average change over 2008-13 is calculated as a geometric average. $f_{i}^{\prime}$ is a vector of pre-determined covariates (see Table 2). Controls in columns (2), (4), (6) have been selected using the "double selection" of Belloni et al. (2014) and the code provided by the authors. Columns (1), (3), (5) include all $f_{i}^{\prime}$, but only coefficients on those that are also "double selected" are shown (a full regression table is available from the authors) ${ }^{*} p<.10{ }^{* *} p<.05{ }^{* * *} p<.01$

manage to qualify as "Convergence" regions and, therefore, receive a substantial amount of financing.

With respect to the quality of institutions, we unfortunately cannot obtain good enough proxies, given that we would need data at the municipality level in order to aggregate them by LLM. To the best of our knowledge, only Barone and Mocetti (2011) developed an indicator of public spending efficiency at this level, but the indicator is available only for a subsample (approximately one fifth) of municipalities for which the required data were available. This prevents us from building a reasonably good proxy given that we would also have to aggregate the different municipalities included in each LLM.

Differently, the 2001 Census allows us to recover the fraction of the population aged 6 or more with at least a high school diploma. Similarly to Becker et al. (2013), we take them as deviations from the average across Southern LLM, and we add this to the 
Table 10 The effects of European structural funds on average growth, controlling for other national funds

\begin{tabular}{|c|c|c|c|c|c|c|}
\hline \multirow{2}{*}{$\begin{array}{l}\text { Average 2008-13 } \\
\text { growth in: }\end{array}$} & (1) & $(2)$ & (3) & (4) & (5) & (6) \\
\hline & \multicolumn{2}{|c|}{ Employment } & \multicolumn{2}{|c|}{ Population } & \multicolumn{2}{|c|}{ House price per sqm } \\
\hline \multirow{2}{*}{$\begin{array}{l}\text { In(cumulative per capita } \\
\text { payments } 07-13 \text { ) }\end{array}$} & -0.0007 & -0.0037 & 0.0001 & -0.0002 & $-0.0113^{* *}$ & $-0.0095^{* *}$ \\
\hline & $(0.0026)$ & $(0.0028)$ & $(0.0008)$ & $(0.0007)$ & $(0.0050)$ & $(0.0047)$ \\
\hline \multirow{2}{*}{$\begin{array}{l}\text { In(cumulative per capita } \\
\text { payments from other } \\
\text { funds 07-13) }\end{array}$} & $0.0008^{*}$ & 0.0001 & 0.0002 & -0.0000 & -0.0006 & 0.0001 \\
\hline & $(0.0004)$ & $(0.0004)$ & $(0.0001)$ & $(0.0001)$ & $(0.0008)$ & $(0.0009)$ \\
\hline Additional controls & All $f_{i}^{\prime}$ & $\begin{array}{l}\text { Chosen by } \\
\text { double selection }\end{array}$ & All $f_{i}^{\prime}$ & $\begin{array}{l}\text { Chosen by } \\
\text { double selection }\end{array}$ & All $f_{i}^{\prime}$ & $\begin{array}{l}\text { Chosen by } \\
\text { double } \\
\text { selection }\end{array}$ \\
\hline Obs & 325 & 325 & 325 & 325 & 325 & 325 \\
\hline R2 & 0.5091 & 0.2721 & 0.8407 & 0.7771 & 0.4846 & 0.1146 \\
\hline
\end{tabular}

regression, both linearly and interacted with the payments. ${ }^{13}$ In the annual growth regressions, the interaction term is positive for employment and house prices, but small in economic terms and not statistically significant. It is generally negative for population, but marginally statistically significant (at the 10\% level) only when we add the full set of covariates (results available on request). The patterns are less clear in the average growth specification, but still neither statistically nor economically significant. The aggregate results about the effect of European transfer payments does not seem, therefore, to display a significant heterogeneity by human capital.

This is not necessarily inconsistent with Becker et al. (2013). Indeed, their method allows them to compute, for each country, the share of Objective 1 regions whose human-capital and institutional quality is sufficient for displaying a positive effect of European transfers. For Italy, none of the regions satisfy the criteria for displaying an effect on GDP per-capita growth. Half of them meet the required threshold for a positive effect on investment, but with large statistical imprecision in the potential effect (idem, pg. 57). It is therefore not surprising that the differences of human capital within Southern Italy are not, according to our results, sufficient to generate a sensible heterogeneity in the effects.

\subsection{Specification issues}

In the year-to-year regressions we focused on the contemporary (annual) effects. However, the impact of the payments may take some time to materialize. In Table 11 we re-estimate the regression for annual growth including two lags of the logarithm of percapita payments. ${ }^{14}$ In order to do this, we need to focus only on the 2010-2013 period. In Table 11, columns (1)-(3) show a small but positive effect of the current annual payments on employment, while no effect is found on population or prices. Crucially, lags exhibit minor and not statistically significant coefficients on employment. The first lag seems to have a negative and very modest effect on population and again a negative, but larger effect on house prices. However, both estimates are imprecise and statistically significant only at the $10 \%$ level. Two-year lags are neither economically nor statistically significant. All in all, taking aboard past disbursements seems not to add significantly to the overall picture of ineffectiveness. 
Table 11 The effects of European Structural Funds payments and their lags on annual growth, 2010-2013

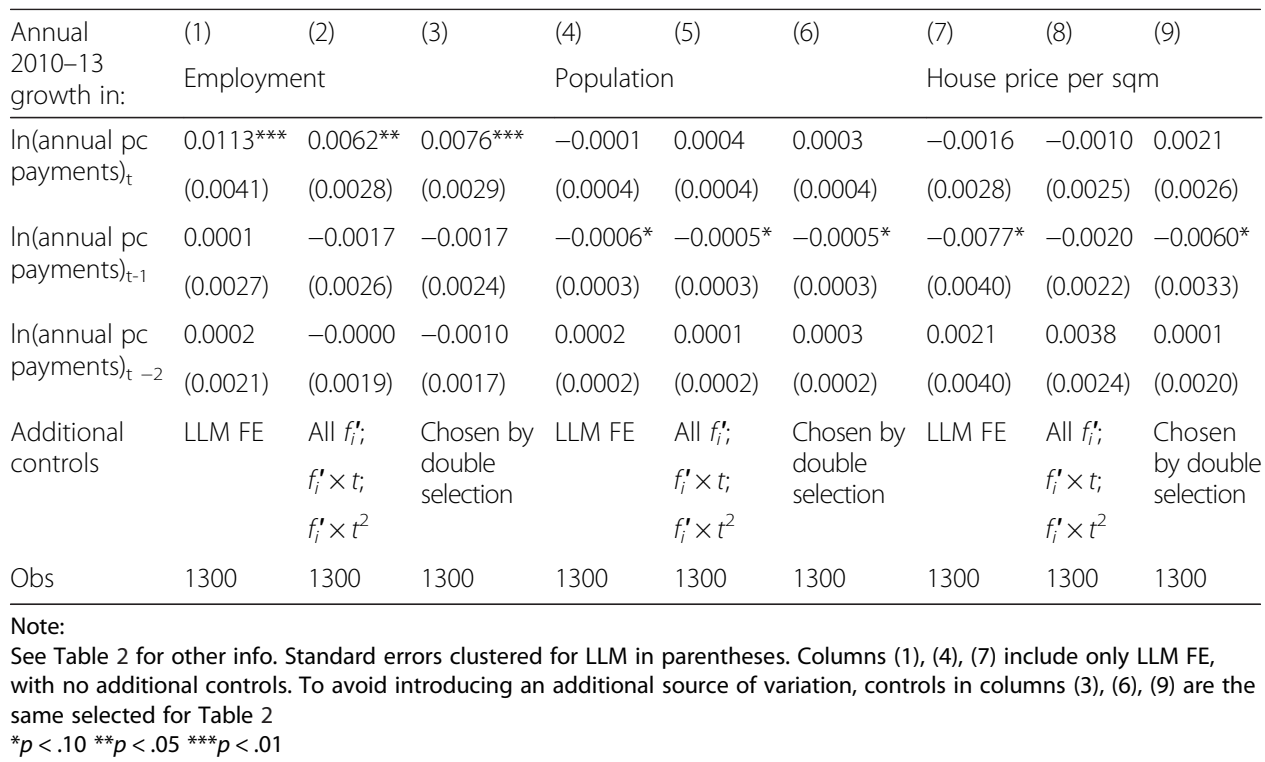

Finally, instead of studying the effect on growth, one may want to look at the elasticity of the level of the outcome with respect to payments related to EU projects. In this case, we need to account at the same time for LLM fixed effects and for heterogeneous time trend. The equivalent of the FE regression for the annual growth in the outcomes is:

$$
\begin{aligned}
& y_{i t}=\exp \left(\delta \ln \left(d_{i t}\right)+\gamma_{t}+u_{i}+g_{i} \times t\right) \eta_{i t} \\
& E\left[\eta_{i s} \mid \ln \left(d_{i t}\right), \gamma_{t}, u_{i}, g_{i} \times t\right]=1 \quad \forall s, t,
\end{aligned}
$$

which can be estimated using Poisson Quasi Maximum Likelihood (PMQL, see Santos-Silva and Tenreyro 2006 for a general discussion and Ciani and Fisher, 2014, for the dif-in-dif case). ${ }^{15}$ The coefficient $\delta$ can be interpreted as the elasticity of the outcome with respect to the per-capita payments. In line with previous estimates, we can also allow for higher order heterogeneous time trends by using the interaction between time trends and fixed time variables and select them using Belloni et al.'s (2014) "double selection." ${ }^{16}$ In this case we show only regressions with the selected variables because Poisson regressions with the entire set do not converge due to the large set of covariates.

Table 12 displays the results. No effect is detected for any of the outcomes, in line with the main results.

\section{Conclusions}

Our analysis suggests that EU Structural Funds disbursed in the South of Italy between 2007 and 2013 had only a limited impact on local measures for employment, population, and house prices. Modest effects on employment are only uncovered for the acceleration/retargeting of payment that started in 2011. Short term effects seem to be associated with the EU money channeled through incentives and the purchase of goods and services. A relevant upshot of our empirical investigation refers to the so called financial execution of the budgets, an issue hotly debated in policy circles. We do not 
Table 12 The elasticity of the current level of outcomes with respect to European Structural Fund payments, 2008-2013

\begin{tabular}{|c|c|c|c|c|c|c|}
\hline \multirow[b]{2}{*}{ Outcome: } & (1) & (2) & (3) & (4) & (5) & (6) \\
\hline & \multicolumn{2}{|l|}{ Employment } & \multicolumn{2}{|l|}{ Population } & \multicolumn{2}{|c|}{ House price per sqm } \\
\hline \multirow{2}{*}{$\begin{array}{l}\text { In(annual pc } \\
\text { payments)t }\end{array}$} & 0.0031 & 0.0048 & -0.0004 & -0.0002 & -0.0065 & -0.0025 \\
\hline & $(0.0039)$ & $(0.0040)$ & $(0.0005)$ & $(0.0005)$ & $(0.0106)$ & $(0.0087)$ \\
\hline $\begin{array}{l}\text { Additional } \\
\text { controls }\end{array}$ & $\begin{array}{l}\text { LLM FE } \\
\text { and specific } \\
\text { linear time } \\
\text { trends }\end{array}$ & $\begin{array}{l}\text { LLM FE, } \\
\text { plus controls } \\
\text { chosen by } \\
\text { double } \\
\text { selection }\end{array}$ & $\begin{array}{l}\text { LLM FE } \\
\text { and specific } \\
\text { linear time } \\
\text { trends }\end{array}$ & $\begin{array}{l}\text { LLM FE, } \\
\text { plus controls } \\
\text { chosen by } \\
\text { double selection }\end{array}$ & $\begin{array}{l}\text { LLM FE and } \\
\text { specific linear } \\
\text { time trends }\end{array}$ & $\begin{array}{l}\text { LLM FE, plus } \\
\text { controls chosen } \\
\text { by double } \\
\text { selection }\end{array}$ \\
\hline Obs & 1950 & 1950 & 1950 & 1950 & 1950 & 1950 \\
\hline
\end{tabular}

See Table 2 for other info. Standard errors clustered for LLM in parentheses. Estimates obtained using Poisson Quasi Maximum Likelihood. Controls in columns (3), (6), (9) have been chosen using the "double selection" method (Belloni et al. 2014, and the code provided by the authors) on the reduced forms for In(annual pc payments) t $_{t}$ and for the logarithm of the outcome. Coefficients on selected covariates are available on request ${ }^{*} p<.10{ }^{* *} p<.05{ }^{* * *} p<.01$

find evidence that speeding-up disbursements would have had a more beneficial impact on the local economic outcomes that we consider. A joint reading of two results, the one related to the 2011 "Piano di Azione e Coesione" and the one referring to the speed of the financial execution would suggest that the effects of the former are mostly related to the refocusing rather than the acceleration per se. Overall, our findings underscore that the targets and design of the interventions have to be reformed to increase their effectiveness.

It is worth mentioning, though, the two main caveats of our exercise. Firstly, our estimates are basically diff-in-diffs estimates, where the treatment is taken to be continuous. In this set-up, and because of the concomitant severe economic crisis, the main challenge is to reduce the role of omitted time-varying variables. We try to accomplish this job by controlling for an extensive list of LLM-specific traits that should help in predicting local trends. Obviously, one cannot be ensured that all the sources of local dynamics are successfully differentiated away, even though we control for all the local traits that should reasonably have a role in explaining the severity of the crisis in a given local context. We also believe that the limitations of the empirical framework we adopt should be weighed against the benefits of having timely empirical evidence on the effectiveness of the 2007-13 EU Structural Funds. Having such evidence while the design of the interventions for the next programing period (2014-20) of the EU Structural Funds is under way should be extremely valuable for policy making.

Secondly, we focus on a single area, the South of Italy, that has been severely hit by the economic crisis. The extent to which our results might provide lessons for other EU countries or timespan with less dramatic economic conditions is something that is left to further inquiries. Furthermore, as we currently have to limit our analysis to the six years of the programing period, future research projects can try to study whether stronger effects might be found in the longer run.

\section{Endnotes}

${ }^{1}$ The definition was built using the same algorithm previously used in 1991 (Istat 1997). The 2001 map was recently revised using the new method that was implemented starting with the 2011 Census (see http://www.istat.it/en/archive/142790; last access: 
30/06/2015). At the moment of writing, the data at the local level that have been used in this paper are not available for this new definition.

${ }^{2}$ Because of the dramatic economic crisis, we are mostly concerned with the downward bias due to time-varying omitted at the local level. Obviously, one could also imagine that the bias goes in the other direction. For instance, the most efficient local administrations could have obtained more money, as the EU programs managed by them were executed in a faster way.

${ }^{3}$ These variables have been included in the spirit of Bartik (1991), who calculates local shocks by interacting the begin-of-the-period industry composition with the nationwide changes and industry-specific changes in employment. The data were obtained from the ASIA archive, which collects the entire population of private sector firms and plants. Unfortunately, these data are not currently available at the industry-LLM level for 2013. See Section 7.1 for the discussion of results using ASIA to build an alternative outcome variable.

${ }^{4}$ We used the Stata program lassoShooting written by them.

${ }^{5}$ www.opencoesione.gov.it

${ }^{6}$ In some cases, the projects contain information about multiple geographical levels. For example, it may list both a set of municipalities and some provinces (or an entire region). In these cases, we chose to give priority to the information pertaining to the most disaggregated level. For instance, in the example just discussed, we only considered the municipalities explicitly mentioned, ignoring the information on provinces or regions.

${ }^{7}$ Another region, Basilicata, is in the phasing out phase.

${ }^{8}$ The calculation for the growth in employment is performed as 0.007 (the coefficient on logarithm payments) times the logarithm of 1.7 (170\%). The cost per unit increase evaluated at the average would be somewhat larger (90,000 euros) than the one for a 10 percent increase in payments.

${ }^{9}$ One potential concern with the procedure of sample-splitting implemented in Tables $4-6$ is that some statistically significant results are likely to be found also by chance. To address this concern, for each estimation method, we jointly test the null that the coefficients on log payments is equal to zero in all couples of years. P-values are generally in line with the conclusions described in the text (see last columns of Tables 4-6).

${ }^{10}$ Given that the explicative variable changes, we run again the "double selection" procedure, but the selected covariates ended up to be the same as in Table 2.

${ }^{11}$ In the baselines, however, we use the disbursements as variable of interest but we also controlled for the allocations.

${ }^{12}$ To avoid introducing different sources of variation in the results, we keep the same list of covariates as in Table 2.

${ }^{13}$ Becker et al. (2013) used the fraction of workers holding at least a high school diploma. Unfortunately, ISTAT does not release data on workers' education at the LLM level, neither from the 2001 Census nor from the annual Labour Force Survey.

${ }^{14}$ Payments may also arrive after the projects have been carried out. In this case, we may want to study the effect of the first lead of the main explicative variables. Note, however, that we have already tested the significance of a lead as part of the test for strict exogeneity in the FE equations and it was never significant.

${ }^{15}$ The alternative is to log-linearize the model and use OLS. However, this method, although standard, is biased under heteroskedasticity, which instead does 
not affect the consistency of PQMLE (Santos-Silva and Tenreyro 2006; Ciani and Fisher 2014).

${ }^{16}$ Formally, the equation becomes (being in levels, we keep the LLM fixed effects):

$$
\begin{gathered}
y_{i t}=\exp \left(\delta \ln \left(d_{i t}\right)+\gamma_{t}+u_{i}+t \times f_{i}^{\prime} \varphi_{1}+t^{2} \times f_{i}^{\prime} \varphi_{2}+t^{3} \times f_{i}^{\prime} \varphi_{3}\right) \eta_{i t} \\
E\left(\eta_{i t} \mid \ln \left(d_{i t}\right), \gamma_{t}, f_{i}^{\prime}, t\right)=1
\end{gathered}
$$

For the selection of covariates, although there are methods for the non-linear cases, here we simplify by log-linearizing the two reduced forms (this is potentially biased, see footnote 15).

\section{Additional file}

Additional file 1: Contains additional results and descriptive statistics. (PDF $740 \mathrm{~kb}$ )

\section{Competing interests}

The IZA Journal of Labor Policy is committed to the IZA Guiding Principles of Research Integrity. The authors declare that they have observed these principles.

\section{Authors' information}

EC is a junior economist at the Regional Economic Research Division of the Bank of Italy, Florence branch; he is also fellow of the Centre for the Analysis of Public Policies at the University of Modena and Reggio Emilia. GdB is a senior economist in the Structural Economic Analysis Directorate of the Bank of Italy.

\section{Acknowledgements}

The views expressed in this paper are those of the authors and do not necessarily correspond to those of the Institution they are affiliated. Part of this work was undertaken while Emanuele Ciani was visiting the Structural Economic Analysis Directorate at the Bank of Italy. We thank an anonymous referee, Luigi Federico Signorini, Paolo Sestito, Giuseppe Albanese, Mara Giua and Enrico Rettore for their useful comments.

Responsible editor: Juan F Jimeno.

\section{Author details}

${ }^{1}$ Bank of Italy, Regional Economic Research Division, Florence Branch, via dell'Oriuolo 37/39, 50122 Firenze, Italy. ${ }^{2}$ Centre for the Analysis of Public Policies, University of Modena and Reggio Emilia, viale Berengario 51, 41121 Modena, Italy. ${ }^{3}$ Bank of Italy, Structural Economic Analysis Directorate, via Nazionale 91, 00184 Roma, Italy.

Received: 24 April 2015 Accepted: 4 August 2015

Published online: 28 October 2015

References

Accetturo A, de Blasio G (2012) Policies for Local Development: an evaluation of Italy's "Patti Territoriali". Reg Sci Urban Econ 42(1-2):15-26. doi:10.1016/j.regsciurbeco.2011.04.005

Accetturo A, de Blasio G, Ricci L (2014) A tale of unwanted outcome: transfers and the local endowments of trust and cooperation. J Econ Behav Organ 102:74-89. doi:10.1016/j.jebo.2014.03.015

Andini M, de Blasio G (2014) Local development that money can't buy: Italy's Contratti di Programma. J Econ Geogr 4:2014. doi:10.1093/jeg/lbu048, first published online

Barca F, McCann P, Rodríguez-Pose A (2012) The case for regional development intervention: place-based versus place-neutral approaches. J Regional Sci 52(1):134-152. doi:10.1111/j.1467-9787.2011.00756.x

Barone G, Mocetti S (2011) Tax morale and public spending inefficiency. Int Tax Public Finance 18(6):724-749. doi:10.1007/s10797-011-9174-z

Bartik TJ (1991) Who Benefits From State and Local Economic Development Policies. W.E. Upjohn Institute for Employment Research, Kalamazoo, Mich

Becker SO, Egger PH, von Ehrlich M (2010) Going NUTS: the effect of EU Structural Funds on regional performance. J Public Econ 94(9-10):578-590. doi:10.1016/j.jpubeco.2010.06.006

Becker SO, Egger PH, von Ehrlich M (2012) Too much of a good thing? On the growth effects of the EU's regional policy. Eur Econ Rev 56(4):648-668. doi:10.1016/j.euroecorev.2012.03.001

Becker SO, Egger PH, von Ehrilich M (2013) Absorptive capacity and the growth and investment effects of regional transfers: a regression discontinuity design with heterogeneous treatment effects. AEJ: Policy 5(4):29-77. doi:10.1257/pol.5.4.29

Belloni A, Chernozhukov V, Hansen C (2014) High-dimensional methods and inference on structural and treatment effects. J Econ Perspect 28(2):29-50. doi:10.1257/jep.28.2.29

Besley T (2004) Paying politicians: theory and evidence. J Eur Econ Assoc 2:193-215. doi:10.1162/154247604323067925

Boldrin M, Canova F (2001) Inequality and convergence in Europe's regions: reconsidering European regional policies. Econ Policy 16(32):205-253

Bronzini R, de Blasio G (2006) Evaluating the impact of investment incentives: the case of Italy's law 488/1992. J Urban Econ 60:327-349 
Cannari A, Faiella I (2008) House prices and housing wealth in Italy. In: Banca d'Italia (ed) Household Wealth in Italy, Rome, Italy

Ciani E, Fisher P (2014) Dif-in-dif estimators for multiplicative treatment effects, Temi di discussione (Economic working papers) 985 , Bank of Italy

European Commission (2008a) Communication from the Commission to the European Council - A European Economic Recovery Plan, Brussels, 26/11/2008

European Commission (2008b) Road to recovery: the Cohesion package - Questions and Answers on the contribution of Cohesion Policy to the European Economic Recovery Plan, MEMO/08/740

Giua M (2014) Spatial discontinuity for the impact assessment of the EU Regional Policy. The case of Italian Objective 1 regions, mimeo, University Roma Tre Department of Economics working paper n. 197

Glaeser E (2008) Cities, agglomeration and spatial equilibrium. Oxford University Press, Oxford

Glaeser E, Gottlieb JD (2008) The economics of place-making policies. Brookings Pap Eco Ac 39(1):155-253. doi:10.1353/eca.0.0005

Istat (1997) I sistemi locali del lavoro 1991, Argomenti n. 10. Istituto Nazionale di Statistica, Rome, Italy

Kline P, Moretti E (2013a) People, Places and Public Policy: Some Simple Welfare Economics of Local Economic Development Programs, NBER Working Paper 19659

Kline P. Moretti E (2013b) Place Based Policies with Unemployment, NBER Working Paper 18758

Krueger A (1974) The political economy of the rent-seeking society. Am Econ Rev 64(3):291-303

Neumark D, Simpson H (2014) Place-Based Policies, NBER Working Paper 20049

Pellegrini G, Terribile F, Tarola O, Muccigrosso T, Busillo F (2013) Measuring the effect of European Regional Policy on Economic Growth: a regression discontinuity approach. Pap Reg Sci 92(1):217-233. doi:10.1111/j.1435-5957.2012.00459.x

Sala-i-Martin X (1996) Regional Cohesion: Evidence and Theories of Regional Growth and Convergence. Eur Econ Rev $X L: 1325-1352$

Santos-Silva JMC, Tenreyro S (2006) The log of gravity. Rev Econ Stat 88(4):641-658. doi:10.1162/rest.88.4.641

Signorini LF, Visco I (2002) L'economia italiana. II Mulino, Bologna

Wooldridge J (2010) Econometric Analysis of Cross Section and Panel Data, 2nd edn. MIT Press, Cambridge, MA

Submit your manuscript to a SpringerOpen ${ }^{\circ}$ journal and benefit from:

- Convenient online submission

Rigorous peer review

- Immediate publication on acceptance

- Open access: articles freely available online

High visibility within the field

Retaining the copyright to your article

Submit your next manuscript at $\boldsymbol{\sim}$ springeropen.com 